\title{
DYNAMIC MODELS OF R\&D, INNOVATION AND PRODUCTIVITY: PANEL DATA EVIDENCE FOR DUTCH AND FRENCH MANUFACTURING
}

\author{
Wladimir Raymond \\ Jacques Mairesse \\ Pierre Mohnen \\ Franz Palm \\ Working Paper 19074 \\ http://www.nber.org/papers/w19074 \\ NATIONAL BUREAU OF ECONOMIC RESEARCH \\ 1050 Massachusetts Avenue \\ Cambridge, MA 02138 \\ May 2013
}

The authors wish to thank the participants of the various seminars where this paper has been presented for their comments and suggestions, in particular Stéphane Robin, Ulya Ulku and Adrian Wood. The views expressed herein are those of the authors and do not necessarily reflect the views of the National Bureau of Economic Research.

At least one co-author has disclosed a financial relationship of potential relevance for this research. Further information is available online at http://www.nber.org/papers/w19074.ack

NBER working papers are circulated for discussion and comment purposes. They have not been peerreviewed or been subject to the review by the NBER Board of Directors that accompanies official NBER publications.

(C) 2013 by Wladimir Raymond, Jacques Mairesse, Pierre Mohnen, and Franz Palm. All rights reserved. Short sections of text, not to exceed two paragraphs, may be quoted without explicit permission provided that full credit, including $(C$ notice, is given to the source. 
Dynamic Models of R\&D, Innovation and Productivity: Panel Data Evidence for Dutch and French Manufacturing Wladimir Raymond, Jacques Mairesse, Pierre Mohnen, and Franz Palm NBER Working Paper No. 19074

May 2013, Revised July 2015

JEL No. C33,C34,C35,L60,O31,O32

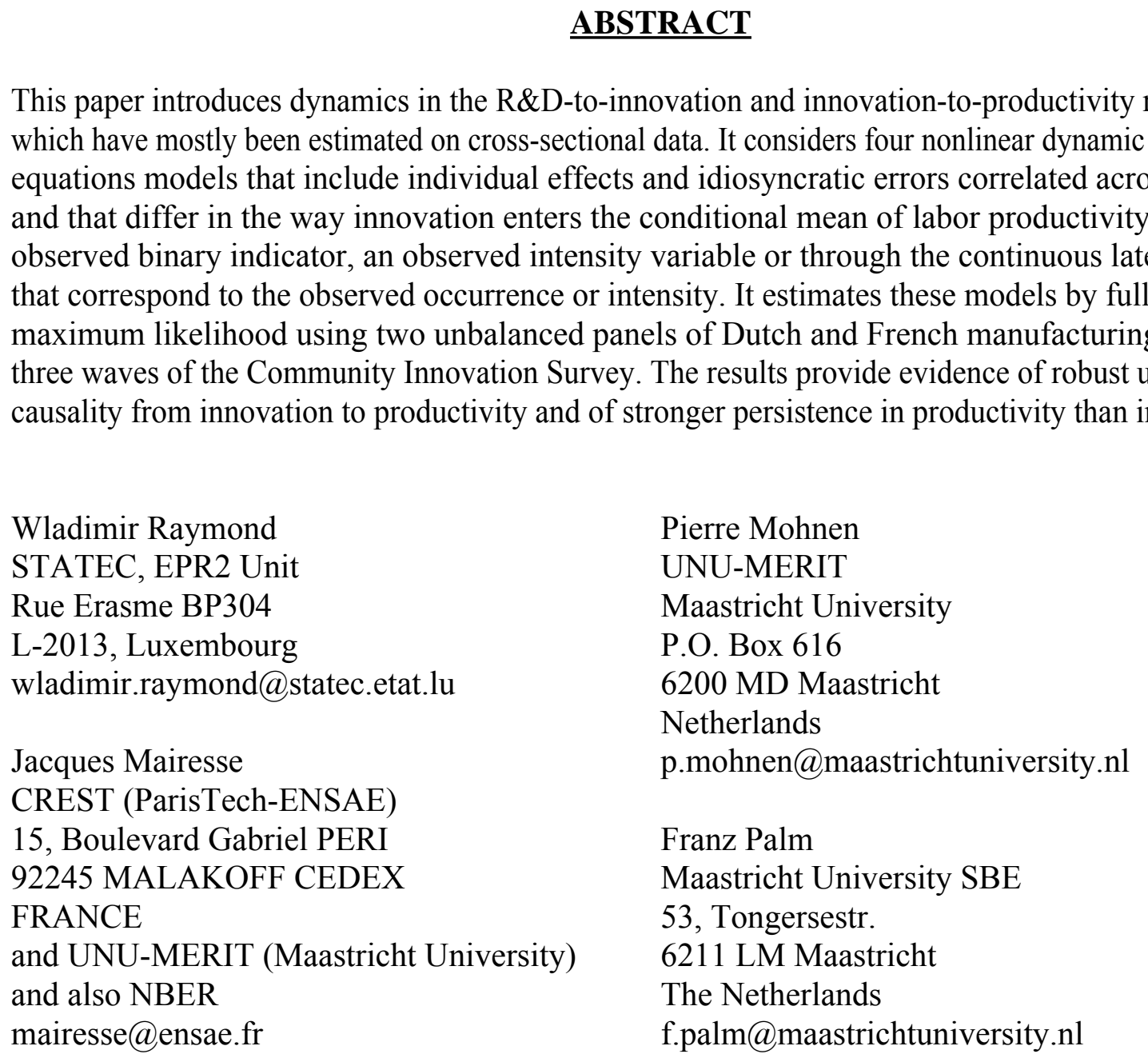




\section{Introduction}

For decades, R\&D and innovation have been recognized by scholars and policy makers as major drivers of country, industry and firm economic performance. Many of the early studies, following the lead of Griliches (1979), used an augmented production function with R\&D capital to estimate the returns to $R \& D$ at the firm level. More recently, many studies relied on innovation survey indicators and on the CDM framework to analyze simultaneously a knowledge production function relating innovation output to $\mathrm{R} \& \mathrm{D}$, and an augmented production function linking productivity to innovation output (Crépon et al., 1998; Mairesse et al., 2005; Griffith et al., 2006). Both the effects of R\&D on innovation output and of innovation output on productivity are usually found to be positive and significant in these studies. Most of them, however, are based on cross-sectional data and cannot take into account the dynamic linkages between innovation and economic performance nor unobserved firm heterogeneity. This is where the present study comes into play. ${ }^{1}$ More specifically, using data from three waves of the Community Innovation Survey (CIS) for France and the Netherlands, we examine whether there is evidence of persistence in firm innovation and productivity and of bidirectional causality between them. ${ }^{2}$

There are several reasons why one should introduce dynamics in the interrelationships between R\&D, innovation and productivity. Firstly, the time lag between a firm's decision to invest in R\&D, the associated R\&D outlays and the resulting innovation success may be substantial because of 'time to build', opportunity cost and uncertainty inherent to the innovation process (Majd and Pindyck, 1987). For example, the studies of knowledge production function using firm panel data, where patents proxy for knowledge, specify a relation of patents to distributed lags of R\&D (Pakes and Griliches, 1980; Hall et al., 1986). Secondly, scholars argue that a successfully innovative firm is more likely than a non-innovating firm to experience innovation success in the future, in other words, that 'success breeds success'. Several papers have investigated the persistence of innovation success, measured by the number of granted patents (Geroski et al., 1997), the introduction of new or significantly improved products (Peters, 2009) or production methods (Flaig and Stadler, 1994), or the share in total sales accounted for by sales of these products (henceforth the share of innovative sales) (Raymond et al., 2010). Thirdly, it is also argued that the economic performance of a firm, especially of a repeatedly innovating firm, is likely to exhibit persistence. For instance, Bailey et al. (1992), Bartelsman and Dhrymes (1998), and Fariñas and Ruano (2005) find strong

\footnotetext{
${ }^{1}$ See also Parisi et al. (2006) and Huergo and Moreno (2011) for two different attempts to go in this direction.

${ }^{2}$ There are important differences between France and the Netherlands, in particular the size of the two countries, the industrial composition, the extent of external trade and institutional and regulatory changes in our study period. It is not clear a priori how these differences impact directly the firm innovation and productivity relationships between the two countries. We consider it interesting and important to compare them for the sake of scientific replication (see Hamermesh, 2007).
} 
evidence of persistence of firm level productivity differentials using transition probabilities on the quintiles or deciles of the distribution of these differentials over time, or using kernel techniques to estimate the conditional distribution of firm level productivity at period $t$ given productivity at period $t-1$. Finally, because of information asymmetry, firms may be more willing to rely on retained earnings rather than to seek external funding for their future innovations (Bhattacharya and Ritter, 1983), implying a feedback effect from productivity to innovation.

To investigate these dynamic aspects, we study four nonlinear dynamic simultaneous equations models that differ in the way that innovation enters the conditional mean of labor productivity: through an observed binary indicator, an observed intensity variable or through the continuous latent variables that correspond to the observed occurrence or intensity. We describe these models in detail in Section 2.

We show in Section 3 how to derive the full information maximum likelihood estimator assuming random effects that are correlated with sufficiently time-varying explanatory variables. More specifically, we take care of the initial conditions problem due to the autoregressive structure of the models and the presence of firm effects using Wooldridge's (2005) 'simple solutions' approach, and we handle multiple integration due to the correlations of firm effects and idiosyncratic errors across equations using Gauss-Hermite quadrature sequentially along the lines of Raymond (2007, chapter 6).

In Section 4, we explain the data on which we base our estimations and provide some descriptive statistics. These data come from three waves of the Dutch and the French Manufacturing Community Innovation Surveys (CIS) for 1994-1996, 1998-2000 and 2002-2004, supplemented by a few firm accounting variables. We work with an unbalanced panel to have a larger sample and thus to weaken possible survivorship biases and to obtain more accurate estimates.

In Section 5 we present our results. For both countries they reveal strong persistence in productivity but weaker persistence in innovation, and they indicate a unidirectional causality running from innovation to labor productivity. Whereas past innovation matters to productivity, the most productive enterprises are not more successful in introducing new or significantly improved products and do not attain larger shares of innovative sales than the least productive ones.

\section{Model specifications}

Our models consist of a knowledge production function and an augmented production function relating respectively innovation output to $R \& D$ and other relevant innovation factors, and productivity to innovation output and other relevant production factors. Four measures of innovation 
output are considered in the analysis. The first is an observed binary variable taking the value one if an enterprise is a product innovator, and zero otherwise. In the innovation survey, a product innovator is a firm that has introduced a new or improved product in the last three years. The second variable is a continuous observed variable, namely the observed innovation intensity, measured by the share of total sales in year $t$ due to products introduced in the last three years, i.e. $t, t-1$ or $t-2$. Although the latter is more informative than the former it is likely to be more affected by important measurement errors. We also consider the two latent innovation output variables that underly respectively the propensity to introduce new or improved products on the market and the potential share of innovative sales. Both latent variables are continuous measures that substitute in one case for a binary variable and in the other case for a continuous variable with corner solution. The latent variable specification assumes there is an underlying true variable which is not necessarily zero when it is not observed (e.g. in case of a small incremental innovation) while the observed specification assumes that innovation is well known and possibly equal to zero. As innovation output later enters as an argument in the production function, it is also not clear whether it is the observed ex-post or the expected ex-ante innovation that should determine labor productivity. There are thus both economic and statistical reasons for preferring one specification over the other. We shall compare all four of them.

\subsection{Knowledge production function (KPF)}

Let $y_{1 i t}^{*}$ denote a latent variable underlying firm $i$ 's $(i=1, \ldots, N)$ propensity to achieve product innovations at period $t\left(t=0_{i}, \ldots, T_{i}\right)$ given past observed occurrence of product innovations $y_{1 i, t-1}$, past labor productivity $y_{3 i, t-1}$, past R\&D and other firm- and market-specific characteristics $\mathbf{x}_{1 i t}$, and unobserved firm heterogeneity $\alpha_{1 i} \cdot{ }^{3}$ Formally

$$
y_{1 i t}^{*}=\vartheta_{11} y_{1 i, t-1}+\vartheta_{13} y_{3 i, t-1}+\boldsymbol{\beta}_{1}^{\prime} \mathbf{x}_{1 i t}+\alpha_{1 i}+\varepsilon_{1 i t},
$$

where $\vartheta_{11}$ and $\vartheta_{13}$ capture the effect of past product innovation occurrence and past productivity on the propensity to innovate, $\boldsymbol{\beta}_{1}^{\prime}$ captures the effects of past $\mathrm{R} \& \mathrm{D}$ and other explanatory variables and $\varepsilon_{1 i t}$ denotes idiosyncratic errors encompassing other time-varying unobserved variables that affect $y_{1 i t}^{*}$. The observed dependent variable, $y_{1 i t}$, corresponding to $y_{1 i t}^{*}$ is defined as

$$
y_{1 i t}=\mathbf{1}\left[y_{1 i t}^{*}>0\right],
$$

\footnotetext{
${ }^{3}$ By letting $t$ vary from $0_{i}$ to $T_{i}$, we allow firms to enter and exit the sample at different periods. $0_{i}$ denotes the first observation of firm $i$ in the unbalanced panel data sample and $T_{i}$ its last observation.
} 
where $\mathbf{1}[]$ denotes the indicator function taking the value one if the condition between squared brackets is satisfied, and zero otherwise.

Let $y_{2 i t}^{*}$ denote the firm's latent share of innovative sales, or potential innovation intensity, given past observed innovation intensity $y_{2 i, t-1}$, past labor productivity $y_{3 i, t-1}$, past R\&D and other firm- and market-specific characteristics $\mathbf{x}_{2 i t}$, and firm-specific effects $\alpha_{2 i}$. Formally

$$
y_{2 i t}^{*}=\vartheta_{22} y_{2 i, t-1}+\vartheta_{23} y_{3 i, t-1}+\boldsymbol{\beta}_{2}^{\prime} \mathbf{x}_{2 i t}+\alpha_{2 i}+\varepsilon_{2 i t},
$$

where the coefficients $\vartheta_{22}$ and $\vartheta_{23}$ capture the effect of past observed share of innovative sales and past labor productivity on the potential innovation intensity, $\boldsymbol{\beta}_{2}^{\prime}$ captures the effect of past R\&D and other explanatory variables and $\varepsilon_{2 i t}$ denotes idiosyncratic errors. The observed counterpart to $y_{2 i t}^{*}$ is defined as

$$
y_{2 i t}=\mathbf{1}\left[y_{1 i t}^{*}>0\right] y_{2 i t}^{*} .
$$

In other words, the share of innovative sales of firm $i$ is observed to be positive in period $t$ if its innovation propensity is sufficiently large in that period. If not, the share of innovative sales is set equal to zero.

The product innovation indicator and the share of innovative sales variables are taken from the innovation survey of the two countries. Since the share of innovative sales lies within the unit interval, we use a logit transformation in the estimation in order to normalize it over the entire set of real numbers. ${ }^{4}$

The set of other explanatory variables includes the $\log \mathrm{R} \& \mathrm{D}$ per employee, the log market share, and size, industry and time dummy variables. ${ }^{5}$ Due to the lengthy nature of research and innovation activities, we use lagged R\&D to explain innovation occurrence and innovation intensity. We also thought it better to only consider R\&D expenditure for firms that declare investing continuously in R\&D. ${ }^{6}$ We include a lagged dummy variable for non-continuous R\&D performers to compensate for the fact that for those firms we put the R\&D expenditure equal to zero. Market share is used at the three digit industry level as a measure of relative size that can reflect market power. It is lagged in order to avoid possible endogeneity concerns (due in particular to measurement errors in firm sales which would affect both our market share and productivity variables). ${ }^{7}$ We take employment

\footnotetext{
${ }^{4}$ Zero values of the share of innovative sales are replaced by a positive value $\tau_{1}$ smaller than the minimum positive observed value of that variable, and values one are replaced by a positive value $\tau_{2}$ higher than the second largest observed value. These choices have a negligible effect on our estimates.

${ }^{5}$ In some specifications, we have also three indicators of the distance to the productivity frontier. We find, however, that they are not statistically significant (see Appendix D).

${ }^{6} \mathrm{R} \& \mathrm{D}$ expenditure is likely to be a reasonable proxy of $\mathrm{R} \& \mathrm{D}$ capital for these firms. If we could construct a measure of $R \& D$ capital stock, it would be a better measure to use. We cannot, however, for lack of enough observations over time.

${ }^{7}$ The market share of a firm is defined as the ratio of its sales over the total sales of the three digit industry it
} 
as our measure of firm absolute size, and since the relation between innovation and size may be nonlinear, we use four size class indicators: small enterprises (\# employees $\leq 50)$, medium-sized enterprises $(50<\#$ employees $\leq 250)$, large enterprises $(250<\#$ employees $\leq 500)$ and very large enterprises $(500<\#$ employees), the fourth class being considered as the reference. We control for industry effects, according to the OECD (2007) technology-based classification of high-tech, medium-high-tech, medium-low-tech, and low-tech industries, using three dummy variables for the first three industry categories and taking low-tech industries as the reference. Such industryspecific effects capture differences in technological opportunities (it is easier to innovate in certain industries than in others) and in intensity of competition (which is expected to be higher in hightech than in low-tech industries). Since our panel consists only of three periods and we need one for the lagged variables, we need only include a time dummy variable for the period 1998-2000, with 2002-2004 being the reference. This time dummy controls for macroeconomic shocks and for inflation.

\subsection{Augmented production function (APF)}

As in the great majority of studies, we assume a Cobb-Douglas APF that we write in terms of a log linear productivity equation relating labor productivity to labor (i.e., we do not assume a constant scale elasticity), physical capital per employee (proxied here by physical investment due to the unavailability of a stock measure), and innovation output. We consider four specifications where we explain productivity by latent innovation (i.e. the propensity to achieve product innovations or potential innovation intensity) or by observed innovation (i.e. innovation occurrence or observed innovation intensity). In all cases we also condition current labor productivity on its past values and control for unobserved heterogeneity through firm effects. Thus, we can write

$$
\begin{aligned}
& y_{3 i t}=\vartheta_{33} y_{3 i, t-1}+\boldsymbol{\beta}_{3}^{\prime} \mathbf{x}_{3 i t}+\gamma_{j} y_{j i t}^{*}+\alpha_{3 i}+\varepsilon_{3 i t}, \\
& y_{3 i t}=\vartheta_{33} y_{3 i, t-1}+\boldsymbol{\beta}_{3}^{\prime} \mathbf{x}_{3 i t}+\gamma_{j} y_{j i t}+\alpha_{3 i}+\varepsilon_{3 i t},
\end{aligned}
$$

with $j=1$ or 2 where innovation propensity $\left(y_{1 i t}^{*}\right)$ or potential innovation intensity $\left(y_{2 i t}^{*}\right)$ explains labor productivity in equation (2.5a), and innovation occurrence $\left(y_{1 i t}\right)$ or observed innovation intensity $\left(y_{2 i t}\right)$ explains labor productivity in equation $(2.5 \mathrm{~b})$. The coefficient $\vartheta_{33}$ captures the effect of past labor productivity on current labor productivity, $\boldsymbol{\beta}_{3}^{\prime}$ captures the effect of standard

belongs to. The latter is obtained by adding up the sales of all firms in our sample that belong to that industry after multiplying them by an appropriate raising factor in order to have the total sales of the industry in the population. As we shall see, a combination of a census and a stratified random sampling is used to collect the data. In the latter case, the raising factor is calculated for each stratum as the ratio of the number of firms in the population of that stratum over the number of firms in the corresponding stratum sample. 
input variables, i.e. employment and physical investment per employee, $\gamma_{j}$ captures the effect of innovation output on labor productivity, and $\alpha_{3 i}$ and $\varepsilon_{3 i t}$ denote time-invariant firm effects and idiosyncratic errors. We also control for industry and time effects as in the KPF equations.

\section{$3 \quad$ Full information maximum likelihood estimation (FIML)}

We shall now explain how to derive the FIML estimator, that is how to take care of the initial conditions problem due to the autoregressive structure of the models and the presence of firm effects, how to write the likelihood function, and how to handle the multiple integration due to the correlations of firm effects and idiosyncratic errors across equations.

\subsection{Initial conditions}

The initial conditions problem stems from the fact that the first observed value of the lagged dependent variables is correlated with the individual effects. Ignoring or inadequately accounting for this correlation results in a bias of the effect of the lagged dependent variables. Several solutions have been proposed in the econometric literature. We follow the one suggested by Wooldridge (2005).

Wooldridge's 'simple solutions' have been originally applied to autoregressive nonlinear singleequation models with individual effects. We adapt the approach to a model with multiple equations. In other words, we project in each equation the individual effects on the first observation of the corresponding dependent variables and on the observed history of the explanatory variables. Formally

$$
\begin{aligned}
& \alpha_{1 i}=b_{10}+\boldsymbol{b}_{11}^{\prime} \boldsymbol{y}_{1 i 0_{i}}+\boldsymbol{b}_{12}^{\prime} \mathbf{x}_{1 i}+a_{1 i}, \\
& \alpha_{2 i}=b_{20}+\boldsymbol{b}_{21}^{\prime} \boldsymbol{y}_{2 i 0_{i}}+\boldsymbol{b}_{22}^{\prime} \mathbf{x}_{2 i}+a_{2 i}, \\
& \alpha_{3 i}=b_{30}+\boldsymbol{b}_{31}^{\prime} \boldsymbol{y}_{3 i 0_{i}}+\boldsymbol{b}_{32}^{\prime} \mathbf{x}_{3 i}+a_{3 i},
\end{aligned}
$$

where $\boldsymbol{y}_{k i 0_{i}}(k=1,2,3)$ represents the initial values of the dependent variables, $\mathbf{x}_{k i}=\left(\mathbf{x}_{k i 0_{i}+1}, \ldots\right.$, $\left.\mathbf{x}_{k i T_{i}}\right)^{\prime}$ represents the history of (in principle all) the observations of the time-varying explanatory variables, and $\boldsymbol{a}_{i}=\left(a_{1 i}, a_{2 i}, a_{3 i}\right)^{\prime}$ denotes the vector of projection errors assumed orthogonal to $\boldsymbol{y}_{k i 0_{i}}, \mathbf{x}_{k i}$ and $\boldsymbol{\varepsilon}_{i t}=\left(\varepsilon_{1 i t}, \varepsilon_{2 i t}, \varepsilon_{3 i t}\right)^{\prime}$. The ancillary parameters $b_{k 0}, \boldsymbol{b}_{k 1}$ and $\boldsymbol{b}_{k 2}$ are to be estimated alongside the parameters of interest.

Three important remarks are in order regarding equations (3.1)-(3.3). Firstly, if the coefficient vectors $\boldsymbol{\beta}_{k}$ contain intercepts, only the sums of those intercepts and $b_{k 0}$ are identified. Secondly, 
if the explanatory variables are time-invariant or do not show sufficient within variation, then the coefficients $\boldsymbol{b}_{k 2}$ and $\boldsymbol{\beta}_{k}$ cannot be separately identified. As a result, only the sufficiently time-varying explanatory variables enter equations (3.1)-(3.3). Thirdly, in order to discriminate between the effect of the lagged dependent variables and that of the initial values, given the unbalancedness of the panel, we actually have to include in equations (3.1)-(3.3) two types of initial values with different coefficients for firms present in all three waves and for those present only in two waves. Following Wooldridge (2005) we make the following distributional assumptions: $\boldsymbol{\varepsilon}_{i t \mid \boldsymbol{y}_{i, t-1}, \mathbf{x}_{i t}, \boldsymbol{\alpha}_{i}} \stackrel{i i d}{\sim} \operatorname{Normal}\left(\mathbf{0}, \boldsymbol{\Sigma}_{\boldsymbol{\varepsilon}}\right) ; \boldsymbol{a}_{i \mid \boldsymbol{y}_{i_{i}}, \mathbf{x}_{i}} \stackrel{i i d}{\sim} \boldsymbol{N o r m a l}\left(\mathbf{0}, \boldsymbol{\Sigma}_{\boldsymbol{a}}\right)$ where $\boldsymbol{\Sigma}_{\boldsymbol{\varepsilon}}$ and $\boldsymbol{\Sigma}_{\boldsymbol{a}}$ are given by

$$
\boldsymbol{\Sigma}_{\varepsilon}=\left(\begin{array}{ccc}
1 & & \\
\rho_{\varepsilon_{1} \varepsilon_{2}} \sigma_{\varepsilon_{2}} & \sigma_{\varepsilon_{2}}^{2} & \\
\rho_{\varepsilon_{1} \varepsilon_{3}} \sigma_{\varepsilon_{3}} & \rho_{\varepsilon_{2} \varepsilon_{3}} \sigma_{\varepsilon_{2}} \sigma_{\varepsilon_{3}} & \sigma_{\varepsilon_{3}}^{2}
\end{array}\right), \boldsymbol{\Sigma}_{\boldsymbol{a}}=\left(\begin{array}{ccc}
\sigma_{a_{1}}^{2} & \\
\rho_{a_{1} a_{2}} \sigma_{a_{1}} \sigma_{a_{2}} & \sigma_{a_{2}}^{2} & \\
\rho_{a_{1} a_{3}} \sigma_{a_{1}} \sigma_{a_{3}} & \rho_{a_{2} a_{3}} \sigma_{a_{2}} \sigma_{a_{3}} & \sigma_{a_{3}}^{2}
\end{array}\right)
$$

and are also to be estimated.

\subsection{Likelihood}

We now derive the likelihood functions. For simplicity, we provide the expressions explicitly only for the specifications where $y_{1 i t}^{*}$ or $y_{1 i t}$ (respectively the latent propensity to achieve product innovations and the observed indicator of innovation occurrence) enters the augmented production function. Those with $y_{2 i t}^{*}$ or $y_{2 i t}$ are presented in Appendix B.

\section{Model with latent innovation propensity}

The model with latent innovation propensity as a predictor of labor productivity consists of equations (2.1)-(2.4) and (2.5a) with $j=1$ in equation (2.5a). These equations constitute the structural form of the model. Since $y_{1 i t}^{*}$ is unobserved, we cannot, unlike in simultaneous equations models with observed explanatory variables, derive the likelihood function directly where the dependent variable is included as a regressor. As a result, FIML estimates can be obtained only through the likelihood function of the reduced form of the model. The reduced-form equations are given by equations (2.1)-(2.4) and

$$
y_{3 i t}=\vartheta_{33} y_{3 i, t-1}+\boldsymbol{\beta}_{3}^{\prime} \mathbf{x}_{3 i t}+\gamma_{1}\left[\vartheta_{11} y_{1 i, t-1}+\vartheta_{13} y_{3 i, t-1}+\boldsymbol{\beta}_{1}^{\prime} \mathbf{x}_{1 i t}\right]+\underbrace{\gamma_{1} \alpha_{1 i}+\alpha_{3 i}}_{\underline{\underline{\alpha_{3 i}}}}+\underbrace{\gamma_{1} \varepsilon_{1 i t}+\varepsilon_{3 i t}}_{\underline{\underline{\epsilon_{3 i t}}}},
$$


where $y_{1 i t}^{*}$ has been replaced by its right-hand side expression of equation (2.1). ${ }^{8}$ The individual effects and the idiosyncratic errors of the reduced form are given by $\underline{\boldsymbol{\alpha}_{i}}=\left(\alpha_{1 i}, \alpha_{2 i}, \underline{\alpha_{3 i}}\right)^{\prime}$ and $\underline{\varepsilon_{i t}}=\left(\varepsilon_{1 i t}, \varepsilon_{2 i t}, \underline{\varepsilon_{3 i t}}\right)^{\prime}$, where $\underline{\alpha_{3 i}}$ and $\underline{\varepsilon_{3 i t}}$ are defined in equation (3.5). After replacing $\alpha_{1 i}, \alpha_{2 i}$ and $\alpha_{3 i}$ by their expressions (3.1) to (3.3) into equations (2.1), (2.3) and (3.5), we obtain the projection errors of the reduced form as $\underline{\boldsymbol{a}_{i}}=\left(a_{1 i}, a_{2 i}, \underline{a_{3 i}}\right)^{\prime}$ with $\underline{a_{3 i}}=\gamma_{1} a_{1 i}+a_{3 i}$. Since the structural form idiosyncratic errors and projection errors are both normally distributed, their reduced-form counterparts are also normally distributed with means zero and covariance matrices $\underline{\boldsymbol{\Sigma}_{\varepsilon}}$ and $\underline{\boldsymbol{\Sigma}_{\boldsymbol{a}}}$ given by

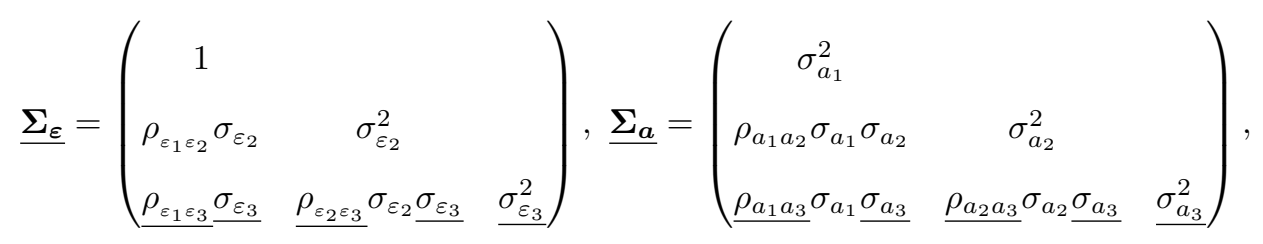

where the underlined components of $\underline{\boldsymbol{\Sigma}_{\varepsilon}}$ and $\underline{\boldsymbol{\Sigma}_{\boldsymbol{a}}}$ are nonlinear functions of their structural form counterparts and are given by

$$
\begin{aligned}
\underline{\sigma_{\varepsilon_{3}}^{2}} & =\gamma_{1}^{2}+\sigma_{\varepsilon_{3}}^{2}+2 \gamma_{1} \rho_{\varepsilon_{1} \varepsilon_{3}} \sigma_{\varepsilon_{3}}, & \underline{\sigma_{a_{3}}^{2}} & =\gamma_{1}^{2} \sigma_{a_{1}}^{2}+\sigma_{a_{3}}^{2}+2 \gamma_{1} \rho_{a_{1} a_{3}} \sigma_{a_{1}} \sigma_{a_{3}}, \\
\underline{\rho_{\varepsilon_{1} \varepsilon_{3}}} & =\frac{\gamma_{1}+\rho_{\varepsilon_{1} \varepsilon_{3}} \sigma_{\varepsilon_{3}}}{\left(\gamma_{1}^{2}+\sigma_{\varepsilon_{3}}^{2}+2 \gamma_{1} \rho_{\varepsilon_{\varepsilon_{1}} \varepsilon_{3}} \sigma_{\varepsilon_{3}}\right)^{\frac{1}{2}}}, & \underline{\rho_{a_{1} a_{3}}} & =\frac{\gamma_{1} \sigma_{a_{1}}+\rho_{a_{1} a_{3}} \sigma_{a_{3}}}{\left(\gamma_{1}^{2} \sigma_{a_{1}}^{2}+\sigma_{a_{3}}^{2}+2 \gamma_{1} \rho_{a_{1} a_{3}} \sigma_{a_{1}} \sigma_{a_{3}}\right)^{\frac{1}{2}}}, \\
\underline{\rho_{\varepsilon_{2} \varepsilon_{3}}} & =\frac{\gamma_{1} \rho_{\varepsilon_{1} \varepsilon_{2}}+\rho_{\varepsilon_{\varepsilon_{2} \varepsilon_{3}}} \sigma_{\varepsilon_{3}}}{\left(\gamma_{1}^{2}+\sigma_{\varepsilon_{3}}^{2}+2 \gamma_{1} \rho_{\varepsilon_{1} \varepsilon_{3}} \sigma_{\varepsilon_{3}}\right)^{\frac{1}{2}}}, & \underline{\rho_{a_{2} a_{3}}} & =\frac{\gamma_{1} \rho_{a_{1} a_{2}} \sigma_{a_{1}}+\rho_{a_{2} a_{3}} \sigma_{a_{3}}}{\left(\gamma_{1}^{2} \sigma_{a_{1}}^{2}+\sigma_{a_{3}}^{2}+2 \gamma_{1} \rho_{a_{1} a_{3}} \sigma_{a_{1}} \sigma_{a_{3}}\right)^{\frac{1}{2}}} .
\end{aligned}
$$

The individual likelihood function of the reduced form conditional on $\underline{\boldsymbol{a}_{i}}$, denoted by $l_{1 i \underline{\underline{\boldsymbol{a}_{i}}}}$, is given by

$$
\begin{aligned}
l_{1 i \underline{\boldsymbol{a}_{i}}}=\prod_{t=0_{i}+1}^{T_{i}} & {\left[\int_{-\infty}^{-\left(A_{1 i t}+a_{1 i}\right)} \int_{-\infty}^{\infty} h_{3}\left(\varepsilon_{1 i t}, \varepsilon_{2 i t}, y_{3 i t}\right) d \varepsilon_{1 i t} d \varepsilon_{2 i t}\right]^{1-y_{1 i t}} } \\
& {\left[\int_{-\left(A_{1 i t}+a_{1 i}\right)}^{\infty} h_{3}\left(\varepsilon_{1 i t}, y_{2 i t}, y_{3 i t}\right) d \varepsilon_{1 i t}\right]^{y_{1 i t}} }
\end{aligned}
$$

where $h_{3}$ denotes the density function of the trivariate normal distribution and $A_{1 i t}$ is defined as

$$
A_{1 i t} \equiv \vartheta_{11} y_{1 i, t-1}+\vartheta_{13} y_{3 i, t-1}+\boldsymbol{\beta}_{1}^{\prime} \mathbf{x}_{1 i t}+b_{10}+\boldsymbol{b}_{11}^{\prime} \boldsymbol{y}_{1 i 0_{i}}+\boldsymbol{b}_{12}^{\prime} \mathbf{x}_{1 i}
$$

\footnotetext{
${ }^{8}$ In the econometric literature on simultaneous equations models, equation (3.5) is referred to as restricted reduced form when written with all the parameters of the structural form and unrestricted reduced form when written with the underlined parameters. In the latter case, $\gamma_{1} \vartheta_{11}$ would constitute a new coefficient, say $\vartheta_{11}$. The restricted reduced form is of interest in our analysis.
} 
The first product in equation (3.8) represents the contribution of a non-product innovator to the likelihood function and can be rewritten as $h_{1}\left(y_{3 i t}\right) \int_{-\infty}^{-\left(A_{1 i t}+a_{1 i}\right)} h_{1}\left(\varepsilon_{1 i t} \mid y_{3 i t}\right) d \varepsilon_{1 i t} \cdot{ }^{9}$ The second product represents the contribution of a product innovator and is equal to $h_{1}\left(y_{2 i t} \mid y_{3 i t}\right) h_{1}\left(y_{3 i t}\right)$ $\int_{-\left(A_{1 i t}+a_{1 i}\right)}^{\infty} h_{1}\left(\varepsilon_{1 i t} \mid y_{2 i t}, y_{3 i t}\right) d \varepsilon_{1 i t}$. These single integrals are univariate cumulative distribution functions (CDFs) of the normal distribution, and are shown to be respectively (see Kotz et al., 2000)

$$
\begin{aligned}
& \Phi_{1}\left(\frac{-A_{1 i t}-a_{1 i}-\rho_{\varepsilon_{1} \varepsilon_{3}}}{\sigma_{\varepsilon_{3}}^{-1}\left(y_{3 i t}-A_{3 i t}-\gamma_{1} A_{1 i t}-\underline{a_{3 i}}\right)}\right) \\
& \Phi_{1}\left(\frac{A_{1 i t}+a_{1 i}+\underline{\rho_{12.3}} \sigma_{\varepsilon_{2}}^{-1}\left(y_{2 i t}-A_{2 i t}-a_{2 i}\right)+\underline{\rho_{13.2}} \underline{\sigma_{\varepsilon_{3}}^{-1}}\left(y_{3 i t}-A_{3 i t}-\gamma_{1} A_{1 i t}-\underline{a_{3 i}}\right)}{\sqrt{1-\underline{R_{1.23}^{2}}}}\right),
\end{aligned}
$$

where $A_{1 i t}$ is given in equation (3.9), $A_{2 i t}$ and $A_{3 i t}$ are given by

$$
\begin{aligned}
& A_{2 i t} \equiv \vartheta_{22} y_{2 i, t-1}+\vartheta_{23} y_{3 i, t-1}+\boldsymbol{\beta}_{2}^{\prime} \mathbf{x}_{2 i t}+b_{20}+\boldsymbol{b}_{21}^{\prime} \boldsymbol{y}_{2 i 0_{i}}+\boldsymbol{b}_{22}^{\prime} \mathbf{x}_{2 i} \\
& A_{3 i t} \equiv \vartheta_{33} y_{3 i, t-1}+\boldsymbol{\beta}_{3}^{\prime} \mathbf{x}_{3 i t}+b_{30}+\boldsymbol{b}_{31}^{\prime} \boldsymbol{y}_{3 i 0_{i}}+\boldsymbol{b}_{32}^{\prime} \mathbf{x}_{3 i}
\end{aligned}
$$

and $\underline{\rho_{12.3}}, \underline{\rho_{13.2}}$, and $\underline{R_{1.23}^{2}}$ are given by

$$
\underline{\rho_{12.3}} \equiv \frac{\rho_{\varepsilon_{1} \varepsilon_{2}}-\underline{\rho_{\varepsilon_{1} \varepsilon_{3}}} \underline{\rho_{\varepsilon_{2} \varepsilon_{3}}}}{1-\underline{\rho_{\varepsilon_{2} \varepsilon_{3}}^{2}}}, \underline{\rho_{13.2}} \equiv \frac{\underline{\rho_{\varepsilon_{1} \varepsilon_{3}}}-\rho_{\varepsilon_{1} \varepsilon_{2}} \underline{\rho_{\varepsilon_{2} \varepsilon_{3}}}}{1-\underline{\rho_{\varepsilon_{2} \varepsilon_{3}}^{2}}}, \underline{R_{1.23}^{2}} \equiv \frac{\rho_{\varepsilon_{1} \varepsilon_{2}}^{2}+\rho_{\varepsilon_{1} \varepsilon_{3}}^{2}-2 \rho_{\varepsilon_{1} \varepsilon_{2}} \underline{\rho_{\varepsilon_{1} \varepsilon_{3}}} \underline{\rho_{\varepsilon_{2} \varepsilon_{3}}}}{1-\underline{\rho_{\varepsilon_{2} \varepsilon_{3}}^{2}}}
$$

The final expression of $l_{1 i \mid \underline{\boldsymbol{a}_{i}}}$ is given by

$$
\begin{aligned}
l_{1 i \mid \underline{\boldsymbol{a}_{i}}=} & \prod_{t=0_{i}+1}^{T_{i}} \frac{1}{\sigma_{\varepsilon_{3}}} \phi_{1}\left(\frac{y_{3 i t}-A_{3 i t}-\gamma_{1} A_{1 i t}-\underline{a_{3 i}}}{\underline{\sigma_{\varepsilon_{3}}}}\right)\left[\Phi_{1}\left(\frac{\left.\left.-A_{1 i t}-a_{1 i}-\underline{\rho_{\varepsilon_{1} \varepsilon_{3}}} \frac{\sigma_{\varepsilon_{3}}^{-1}\left(y_{3 i t}-A_{3 i t}-\gamma_{1} A_{1 i t}-\underline{a_{3 i}}\right)}{\sqrt{1-\underline{\rho_{\varepsilon_{1} \varepsilon_{3}}^{2}}}}\right)\right]^{1-y_{1 i t}}}{}\right)\right. \\
& {\left[\Phi_{1}\left(\frac{A_{1 i t}+a_{1 i}+\underline{\rho_{12.3}} \sigma_{\varepsilon_{2}}^{-1}\left(y_{2 i t}-A_{2 i t}-a_{2 i}\right)+\underline{\rho_{13.2}} \underline{\sigma_{\varepsilon_{3}}^{-1}\left(y_{3 i t}-A_{3 i t}-\gamma_{1} A_{1 i t}-\underline{a_{3 i}}\right)}}{\sqrt{1-\underline{R_{1.23}^{2}}}}\right)\right.} \\
& \left.\frac{1}{\sigma_{\varepsilon_{2}} \sqrt{1-\underline{\rho_{\varepsilon_{2} \varepsilon_{3}}^{2}}}} \phi_{1}\left(\frac{y_{2 i t}-A_{2 i t}-a_{2 i}-\frac{\rho_{\varepsilon_{2} \varepsilon_{3}} \sigma_{\varepsilon_{2}}}{\underline{\sigma_{\varepsilon_{3}}}}\left(y_{3 i t}-A_{3 i t}-\gamma_{1} A_{1 i t}-\underline{a_{3 i}}\right)}{\sigma_{\varepsilon_{2}} \sqrt{1-\underline{\rho_{\varepsilon_{2} \varepsilon_{3}}^{2}}}}\right)\right]^{y_{1 i t}}
\end{aligned}
$$

\section{Model with observed innovation incidence}

The model with the observed innovation indicator as a predictor of labor productivity consists of equations (2.1)-(2.4) and (2.5b) with $j=1$ in equation (2.5b). Unlike in the previous model, we

$9 \int_{-\infty}^{\infty} h_{3}\left(\epsilon_{1 i t}, \epsilon_{2 i t}, y_{3 i t}\right) d \epsilon_{2 i t}=h_{2}\left(\epsilon_{1 i t}, y_{3 i t}\right)$ where $h_{2}$ denotes the density of the bivariate normal distribution, and $h_{2}\left(\epsilon_{1 i t}, y_{3 i t}\right)=h_{1}\left(y_{3 i t}\right) h_{1}\left(\epsilon_{1 i t} \mid y_{3 i t}\right)$ where $h_{1}$ denotes the density of the univariate normal distribution. 
insert directly the observed innovation indicator in the likelihood function. ${ }^{10}$

The individual likelihood function of the structural form of this model, conditional on $\boldsymbol{a}_{i}$ and denoted by $l_{2 i \mid \boldsymbol{a}_{i}}$, has a similar expression to $l_{1 i \mid \underline{a}_{i}}$. It is given by

$$
\begin{aligned}
l_{2 i \mid \boldsymbol{a}_{i}=} & \prod_{t=0_{i}+1}^{T_{i}} \frac{1}{\sigma_{\varepsilon_{3}}} \phi_{1}\left(\frac{y_{3 i t}-A_{3 i t}-\gamma_{1} y_{1 i t}-a_{3 i}}{\sigma_{\varepsilon_{3}}}\right)\left[\Phi_{1}\left(\frac{-A_{1 i t}-a_{1 i}-\rho_{\varepsilon_{1} \varepsilon_{3}} \sigma_{\varepsilon_{3}}^{-1}\left(y_{3 i t}-A_{3 i t}-\gamma_{1} y_{1 i t}-a_{3 i}\right)}{\sqrt{1-\rho_{\varepsilon_{1} \varepsilon_{3}}^{2}}}\right)\right]^{1-y_{1 i t}} \\
& {\left[\Phi_{1}\left(\frac{A_{1 i t}+a_{1 i}+\rho_{12.3} \sigma_{\varepsilon_{2}}^{-1}\left(y_{2 i t}-A_{2 i t}-a_{2 i}\right)+\rho_{13.2} \sigma_{\varepsilon_{3}}^{-1}\left(y_{3 i t}-A_{3 i t}-\gamma_{1} y_{1 i t}-a_{3 i}\right)}{\sqrt{1-R_{1.23}^{2}}}\right)\right.} \\
& \left.\frac{1}{\sigma_{\varepsilon_{2}} \sqrt{1-\rho_{\varepsilon_{2} \varepsilon_{3}}^{2}}} \phi_{1}\left(\frac{y_{2 i t}-A_{2 i t}-a_{2 i}-\frac{\rho_{\varepsilon_{2} \varepsilon_{3}} \sigma_{\varepsilon_{2}}}{\sigma_{\varepsilon_{3}}}\left(y_{3 i t}-A_{3 i t}-\gamma_{1} y_{1 i t}-a_{3 i}\right)}{\sigma_{\varepsilon_{2}} \sqrt{1-\rho_{\varepsilon_{2} \varepsilon_{3}}^{2}}}\right)\right]^{y_{1 i t}}
\end{aligned}
$$

where $\rho_{12.3}, \rho_{13.2}$, and $R_{1.23}^{2}$ are derived straightforwardly from equation (3.12) by replacing the underlined correlations by their structural form counterparts, that is

$$
\rho_{12.3} \equiv \frac{\rho_{\varepsilon_{1} \varepsilon_{2}}-\rho_{\varepsilon_{1} \varepsilon_{3}} \rho_{\varepsilon_{2} \varepsilon_{3}}}{1-\rho_{\varepsilon_{2} \varepsilon_{3}}^{2}}, \rho_{13.2} \equiv \frac{\rho_{\varepsilon_{1} \varepsilon_{3}}-\rho_{\varepsilon_{1} \varepsilon_{2}} \rho_{\varepsilon_{2} \varepsilon_{3}}}{1-\rho_{\varepsilon_{2} \varepsilon_{3}}^{2}}, R_{1.23}^{2} \equiv \frac{\rho_{\varepsilon_{1} \varepsilon_{2}}^{2}+\rho_{\varepsilon_{1} \varepsilon_{3}}^{2}-2 \rho_{\varepsilon_{1} \varepsilon_{2}} \rho_{\varepsilon_{1} \varepsilon_{3}} \rho_{\varepsilon_{2} \varepsilon_{3}}}{1-\rho_{\varepsilon_{2} \varepsilon_{3}}^{2}}
$$

\section{Data and descriptive statistics}

The data used in the analysis stem from three waves of the Dutch and the French CIS pertaining to the manufacturing sector, with the exception of the food industry, for the periods 1994-1996 (CIS 2), 1998-2000 (CIS 3) and 2002-2004 (CIS 4). The Dutch and French CIS data are merged respectively with data from the Production Survey (PS) and the 'Enquête Annuelle d'Entreprise' (EAE) that provide information regarding employment, sales and investment. ${ }^{11}$ For each CIS, the merged PS and EAE variables pertain to the last year of the three-year period. We consider enterprises with at least ten employees and positive sales at the end of each period covered by the innovation survey. ${ }^{12}$ Note that one of the particularities of the innovation survey is that, for each period, product innovation occurrence relates to the introduction of a new product over a three-year period, while the actual share of innovative sales pertains to the last year of the period. As a result, a one-period lag corresponds actually to four years, a period sufficiently long to capture

\footnotetext{
${ }^{10} \mathrm{As}$ a matter of fact, adopting this approach is recommended in this case. Indeed, the indicator function that relates the observed dependent variable, $y_{1 i t}$, to the regressors, which would be used in the likelihood function of the reduced form, is discontinuous and the maximization of the likelihood function of the reduced form is unfeasible.

${ }^{11}$ Both Dutch surveys were carried out by the 'Centraal Bureau voor de Statistiek' (CBS) for the whole manufacturing sector and the two French surveys by the 'Service des Statistiques Industrielles' (SESSI) of the French Ministry of Industry for the manufacturing sector excluding the food industry.

${ }^{12}$ We delete enterprises with a share of total R\&D expenditures (intramural + extramural) in total sales greater than $50 \%$ since they are likely to specialize in doing and trading R\&D, hence should be classified in R\&D services not in manufacturing.
} 
medium- to long-term effects. ${ }^{13}$ In this paper we consider as innovators only those firms that have introduced a product new to the firm, but not necessarily new to the market.

In the following Tables 1, 2 and 3, we show some simple descriptive statistics, mostly means, to present our samples and main variables. Table 1 shows, for both countries, the patterns of enterprises' presence in the unbalanced panel after data cleaning. Because of the dynamic structure of the model, an enterprise must be present in at least two consecutive waves of the merged data in order to be included in the analysis. There are 1920 such enterprises in our sample for France and 1228 for The Netherlands. In both countries about one third of the total number of enterprises are present in the three waves.

For each pattern, we report the mean and median employment head counts in the sample and in the population where the head counts in the population are obtained by weighting head counts in the sample using a raising factor obtained after correcting for non-response. Because of the lower cut-off points in The Netherlands and possibly differences in the rates of non-responses in the two countries, the differences in average firm size between the sample and the population are larger for France than for The Netherlands. These differences are, however, smaller in the balanced panel, which is to be expected since firms larger than the cut-off points are all included in the samples and are also more likely to survive during the whole period 1994-2004. Using the unbalanced panel allows us to obtain more precise estimates as more observations for broader types of enterprises are used and also to control partly for survivorship biases as enterprises are allowed to enter and exit the sample at any period. Overall French enterprises are significantly larger than the Dutch ones both in the sample and in the population, in the balanced as well as in the unbalanced panel.

Table 1: Employment in the sample and in the population for each pattern of the unbalanced panel data samples of Dutch and French manufacturing enterprises: CIS 2, CIS 3, and CIS 4

\begin{tabular}{|c|c|c|c|c|c|c|c|c|c|}
\hline \multirow[t]{2}{*}{ Variable $\downarrow$} & \multirow[b]{2}{*}{ Pattern $\rightarrow$} & \multicolumn{4}{|c|}{ France } & \multicolumn{4}{|c|}{ The Netherlands } \\
\hline & & 110 & 111 & 011 & Total & 110 & 111 & 011 & Total \\
\hline \# enterprises & & 504 & 586 & 829 & 1920 & 506 & 411 & 311 & 1228 \\
\hline$\%$ in total & & 26 & 31 & 43 & 100 & 41 & 34 & 25 & 100 \\
\hline \multicolumn{10}{|c|}{ Employment, sample } \\
\hline Mean & & 558 & 1044 & 398 & 691 & 158 & 217 & 335 & 222 \\
\hline Median & & 160 & 663 & 197 & 336 & 75 & 112 & 108 & 96 \\
\hline \multicolumn{10}{|c|}{ Employment, population } \\
\hline Mean & & 215 & 726 & 200 & 334 & 111 & 172 & 197 & 155 \\
\hline Median & & 73 & 405 & 74 & 97 & 56 & 93 & 57 & 68 \\
\hline
\end{tabular}

\footnotetext{
${ }^{13}$ The CIS, PS and EAE data are collected at the enterprise level. A combination of a census and a stratified random sampling is used for each wave of the CIS and the PS. A census is used for the population of Dutch enterprises with at least 50 employees, and a stratified random sampling is used for enterprises with less than 50 employees, where the stratum variables are the enterprise economic activity and employment in head counts. The same cut-off point of 50 employees is applied to each wave of the Dutch CIS and the PS. A similar scheme is used for the French CIS but a cut-off point of 500 employees is used in CIS 2 and 3, and one of 250 employees in CIS 4. The use of different cut-off points in the census/sampling scheme may result in differences across countries in the average size of enterprises in our samples and may affect our estimates. If we had aligned the Dutch sampling with the French sampling we would have lost too many observations for the Netherlands. In the EAE, all enterprises with at least 20 employees are surveyed.
} 
Table 2 gives the means of the non-transformed dependent and explanatory variables for the unbalanced samples and for the subsamples of product innovators. Comparing first all enterprises with product innovators, it appears that in both countries product innovators do not seem to be more productive on average. This is due to the existence among non-product innovators of a few firms with very high values of sales per employee. When we take the logarithms of sales per employee, as we do in our estimating equations, we downweigh outlier values and obtain significantly higher productivities for product innovators in both countries. We also observe that on average in both countries product innovators are larger in terms of employment and have a larger market share.

Comparing now the two countries, we see that Dutch enterprises, either overall or for product innovators only, have on average much higher physical investments per employee, larger market shares but smaller sales per employee than their French counterparts. We also see that the Dutch innovators have on average a significantly higher share of innovative sales but a significantly lower mean R\&D per employee than French innovators. It is finally interesting to note that in France the majority of product innovators and non-innovators are very large in contrast to The Netherlands where they are mostly medium-sized enterprises.

Table 2: Means of dependent and explanatory variables: Unbalanced panel data samples from Dutch and French CIS 2, CIS 3 and CIS 4*

\begin{tabular}{|c|c|c|c|c|}
\hline \multirow[t]{2}{*}{ Variable } & \multicolumn{2}{|c|}{ France } & \multicolumn{2}{|c|}{ The Netherlands } \\
\hline & All enterprises & Product. innov. & All enterprises & Product. innov. \\
\hline Product innovator & 0.59 & - & 0.58 & - \\
\hline Share of innov. sales & - & 0.22 & - & 0.30 \\
\hline Sales/employee ${ }^{\dagger}$ & 220.53 & 215.04 & 184.85 & 180.70 \\
\hline R\&D/employee ${ }^{\ddagger}$ & - & 8.09 & - & 4.68 \\
\hline Investment/employee $^{\dagger}$ & 7.29 & 7.36 & 9.10 & 9.62 \\
\hline Employment & & & & \\
\hline \# emp. & 691.36 & 935.72 & 222.13 & 258.78 \\
\hline Size class & & & & \\
\hline$\#$ emp. $\leq 50$ & 0.13 & 0.06 & 0.20 & 0.14 \\
\hline $50<\#$ emp. $\leq 250$ & 0.29 & 0.21 & 0.63 & 0.65 \\
\hline $250<\#$ emp. $\leq 500$ & 0.20 & 0.22 & 0.08 & 0.11 \\
\hline $500<\#$ emp. & 0.39 & 0.51 & 0.09 & 0.10 \\
\hline Market share (\%) & 1.52 & 1.86 & 1.66 & 2.01 \\
\hline \# observations & 4427 & 2618 & 2867 & 1670 \\
\hline
\end{tabular}

Table 3 gives the same statistics as Table 2 but separately for each period of our unbalanced panel. ${ }^{14}$ For both countries, we observe a significant decrease in the proportion of product innovators and in the mean share of innovative sales between 1994 and 2004. The marked increase of the

\footnotetext{
${ }^{14}$ For each country, the figures of the various columns of Table 3 are not straightforwardly comparable as there may be a "wave" effect due to cyclical effects or changes in the wording or in the sampling scheme of the questionnaire. It is therefore important to control for this effect by including wave-specific dummies, which we achieve in the estimation of the various models.
} 
share of innovative sales between the last two periods for France is not large enough to offset the large decrease that occurs between the first two periods. We also see, for both countries, a strong increase in the mean nominal sales per employee and in the mean market share between 1994 and 2004, while on average employment decreases for France and increases for The Netherlands. The growth that we observe in the mean R\&D and physical investment per employee between 1994 and 2004 is relatively modest (and only statistically significant for The Netherlands). Although the differences between the means of the main variables across countries are informative, it is important to keep in mind that our estimates are not based on the differences of most of such means but on differences within the two countries, four industry categories as well as within wave survey patterns, since we estimate our models separately for France and The Netherlands and we control for firm effects and also include industry and time dummies in all the model equations, as explained in Section 2 .

Table 3: Means of dependent and explanatory variables for each CIS of the unbalanced panel data samples for France and The Netherlands*

\begin{tabular}{|c|c|c|c|c|c|c|}
\hline \multirow[t]{2}{*}{ Variable } & \multicolumn{3}{|c|}{ France } & \multicolumn{3}{|c|}{ The Netherlands } \\
\hline & 1994-1996 & $1998-2000$ & $2002-2004$ & 1994-1996 & $1998-2000$ & $2002-2004$ \\
\hline Product innovator & 0.65 & 0.56 & 0.58 & 0.66 & 0.60 & 0.45 \\
\hline $\begin{array}{l}\text { Share of innov. sales, } \\
\text { for product innovator }\end{array}$ & 0.30 & 0.15 & 0.23 & 0.33 & 0.32 & 0.21 \\
\hline Sales/employee ${ }^{\dagger}$ & 158.51 & 230.52 & 254.75 & 149.43 & 170.11 & 254.91 \\
\hline $\mathrm{R} \& \mathrm{D} / \mathrm{employee}^{\ddagger}$ & 7.59 & 7.28 & 8.64 & 3.96 & 4.76 & 5.14 \\
\hline Investment/employee $^{\dagger}$ & 6.44 & 8.12 & 6.83 & 8.58 & 8.01 & 11.61 \\
\hline \multicolumn{7}{|l|}{ Employment } \\
\hline \# emp. & 806.37 & 673.99 & 626.33 & 175.36 & 236.04 & 257.87 \\
\hline \multicolumn{7}{|l|}{ Size class } \\
\hline$\#$ emp. $\leq 50$ & 0.12 & 0.14 & 0.12 & 0.18 & 0.21 & 0.20 \\
\hline $50<\#$ emp. $\leq 250$ & 0.26 & 0.31 & 0.28 & 0.68 & 0.61 & 0.60 \\
\hline $250<\#$ emp. $\leq 500$ & 0.15 & 0.19 & 0.25 & 0.08 & 0.08 & 0.09 \\
\hline $500<\#$ emp. & 0.47 & 0.36 & 0.35 & 0.06 & 0.10 & 0.11 \\
\hline Market share (\%) & 1.38 & 1.45 & 1.73 & 1.30 & 1.75 & 1.97 \\
\hline \# enterprises & 1091 & 1920 & 1416 & 917 & 1228 & 722 \\
\hline
\end{tabular}

\section{$5 \quad$ Estimation results}

We now turn to the results of the estimation of the models. We shall first briefly comment on the general results before discussing the core results of interest, namely the estimated effects of innovation output on productivity and the dynamic interrelations between innovation and productivity. Tables 4 and 5 present the estimation results for the model with latent innovation as a predictor of labor productivity, and Tables 6 and 7 present the results for the model with observed innovation 
Table 4: FIML estimates of the model with latent innovation propensity to explain productivity:

Unbalanced panel data samples from Dutch and French CIS 2, CIS 3 and CIS $4^{\ddagger}$

\begin{tabular}{|c|c|c|c|c|}
\hline \multirow[t]{3}{*}{ Variable } & Slope & (Std. Err.) & Slope & (Std. Err.) \\
\hline & \multicolumn{2}{|c|}{ France } & \multicolumn{2}{|c|}{ The Netherlands } \\
\hline & \multicolumn{4}{|c|}{ Innovation occurrence $t$} \\
\hline Innovation occurrence $_{t-1}$ & $0.070^{\dagger}$ & $(0.042)$ & 0.020 & $(0.068)$ \\
\hline Innovation occurrence $_{0_{i}}, 3$ waves & 0.066 & $(0.045)$ & $0.276^{* *}$ & $(0.075)$ \\
\hline Innovation occurrence $_{0_{i}}, 2$ waves & $0.133^{* *}$ & $(0.026)$ & $0.286^{* *}$ & $(0.045)$ \\
\hline$(\text { Sales/employee })_{t-1}$, in $\log$ & 0.000 & $(0.006)$ & 0.004 & $(0.010)$ \\
\hline$(\mathrm{R} \& \mathrm{D} / \text { employee })_{t-1}$, in log & 0.010 & $(0.011)$ & $0.069^{* *}$ & $(0.018)$ \\
\hline$\left(\mathrm{D}_{\text {non-continuous } \mathrm{R} \& \mathrm{D}}\right)_{t-1}$ & $-0.208^{* *}$ & $(0.027)$ & $-0.233^{* *}$ & $(0.037)$ \\
\hline \multicolumn{5}{|l|}{ Size class } \\
\hline $\mathrm{D}_{\#}$ employees $\leq 50$ & $-0.184^{* *}$ & $(0.051)$ & -0.108 & $(0.067)$ \\
\hline $\mathrm{D}_{50}<\#$ employees $\leq 250$ & $-0.131^{* *}$ & $(0.036)$ & -0.019 & $(0.057)$ \\
\hline $\mathrm{D}_{250<\# \text { employees } \leq 500}$ & -0.037 & $(0.030)$ & $0.121^{\dagger}$ & $(0.072)$ \\
\hline \multirow[t]{2}{*}{ Market share $_{t-1}$, in $\log$} & $0.029^{* *}$ & $(0.009)$ & $0.031^{* *}$ & $(0.011)$ \\
\hline & \multicolumn{4}{|c|}{ Share of innovative sales$_{t}$, in logit } \\
\hline Share of innov. sales $t-1$, in logit & $0.110^{*}$ & $(0.050)$ & 0.043 & $(0.044)$ \\
\hline Share of innov. sales $0_{i}, 3$ waves & 0.064 & $(0.046)$ & $0.132^{* *}$ & $(0.040)$ \\
\hline Share of innov. sales $_{0_{i}}, 2$ waves & $0.185^{* *}$ & $(0.027)$ & $0.174^{* *}$ & $(0.030)$ \\
\hline$(\text { Sales/employee })_{t-1}$, in log & 0.002 & $(0.034)$ & 0.009 & $(0.029)$ \\
\hline$(\mathrm{R} \& \mathrm{D} / \mathrm{employee})_{t-1}$, in $\log$ & $0.069^{\dagger}$ & $(0.035)$ & $0.125^{* *}$ & $(0.034)$ \\
\hline$\left(D_{\text {non-continuous R\&D }}\right)_{t-1}$ & $-0.326^{* *}$ & $(0.010)$ & $-0.252^{* *}$ & $(0.041)$ \\
\hline \multicolumn{5}{|l|}{ Size class } \\
\hline$D_{\#}$ employees $\leq 50$ & 0.329 & $(0.247)$ & 0.303 & $(0.231)$ \\
\hline $\mathrm{D}_{50<\# \text { employees } \leq 250}$ & 0.122 & $(0.164)$ & 0.116 & $(0.189)$ \\
\hline $\mathrm{D}_{250<\# \text { employees }<500}$ & 0.255 & $(0.250)$ & 0.160 & $(0.233)$ \\
\hline \multirow[t]{2}{*}{ Market share $t-1$, in $\log$} & $0.058^{* *}$ & $(0.001)$ & $0.046^{*}$ & $(0.021)$ \\
\hline & \multicolumn{4}{|c|}{ Labor productivity ${ }_{t}$ : sales/employee, in log } \\
\hline$(\text { Sales/employee })_{t-1}$, in $\log$ & $0.531^{* *}$ & $(0.056)$ & $0.319^{* *}$ & $(0.066)$ \\
\hline (Sales/employee $)_{i}, 3$ waves & $0.336^{* *}$ & $(0.056)$ & $0.282^{* *}$ & $(0.066)$ \\
\hline$(\text { Sales/employee })_{0_{i}}, 2$ waves & $0.856^{* *}$ & $(0.012)$ & $0.584^{* *}$ & $(0.024)$ \\
\hline Latent innovation propensity $t$ & $0.074^{* *}$ & $(0.020)$ & $0.121^{* *}$ & $(0.029)$ \\
\hline$(\text { Investment/employee })_{t}$, in log & $0.065^{* *}$ & $(0.006)$ & $0.119^{* *}$ & $(0.012)$ \\
\hline \multirow[t]{2}{*}{ Employment $_{t}$, in log } & $-0.027^{* *}$ & $(0.008)$ & $-0.082^{* *}$ & $(0.018)$ \\
\hline & \multicolumn{4}{|c|}{ Covariance matrix } \\
\hline \multicolumn{5}{|l|}{ Individual effects } \\
\hline$\sigma_{a_{1}}$ & $0.259^{\dagger}$ & $(0.148)$ & $0.470^{* *}$ & $(0.138)$ \\
\hline$\sigma_{a_{2}}$ & $0.745^{* *}$ & $(0.179)$ & $0.680^{* *}$ & $(0.193)$ \\
\hline$\sigma_{a_{3}}$ & $0.096^{* *}$ & $(0.025)$ & $0.160^{* *}$ & $(0.060)$ \\
\hline$\rho_{a_{1} a_{2}}$ & $0.514^{* *}$ & $(0.152)$ & $0.540^{* *}$ & $(0.145)$ \\
\hline$\rho_{a_{1} a_{3}}$ & -0.090 & $(0.408)$ & -0.221 & $(0.336)$ \\
\hline$\rho_{a_{2} a_{3}}$ & 0.158 & $(0.279)$ & 0.064 & $(0.331)$ \\
\hline \multicolumn{5}{|l|}{ Idiosyncratic errors } \\
\hline$\sigma_{\varepsilon_{2}}$ & $2.469^{* *}$ & $(0.076)$ & $1.780^{* *}$ & $(0.096)$ \\
\hline$\sigma_{\varepsilon_{3}}$ & $0.313^{* *}$ & $(0.009)$ & $0.587^{* *}$ & $(0.019)$ \\
\hline$\rho_{\varepsilon_{1} \varepsilon_{2}}$ & \multicolumn{2}{|c|}{0.99 , fixed after grid search } & \multicolumn{2}{|c|}{0.95 , fixed after grid search } \\
\hline $\begin{array}{l}\varepsilon_{1} \varepsilon_{2} \\
\rho_{\varepsilon_{1} \varepsilon_{3}}\end{array}$ & $-0.206^{* *}$ & $(0.071)$ & $-0.237^{* *}$ & $(0.067)$ \\
\hline$\rho_{\varepsilon_{2} \varepsilon_{3}}$ & $-0.208^{* *}$ & $(0.070)$ & $-0.229^{* *}$ & $(0.061)$ \\
\hline \# observations & \multicolumn{2}{|c|}{2505} & \\
\hline Log-likelihood & \multicolumn{2}{|c|}{-5048.917} & \multicolumn{2}{|c|}{-3920.898} \\
\hline
\end{tabular}

${ }^{\ddagger}$ Three dummies of category of industry, a time dummy and an intercept are included in each equation.

Significance levels : $\quad \dagger: 10 \% \quad *: 5 \% \quad * *: 1 \%$

as a predictor of labor productivity. ${ }^{15}$

\footnotetext{
${ }^{15}$ In Tables 4-7, for each wave, the time subscript $t$ pertains to the last year of the wave period for quantitative variables (e.g. share of innovative sales, $R \& D$ intensity, number of employees) and to the whole wave period for binary variables (e.g. innovation occurrence). Yearly observations are unfortunately not available.
} 
Table 5: FIML estimates of the model with latent innovation intensity to explain productivity: Unbalanced panel data samples from Dutch and French CIS 2, CIS 3 and CIS $4^{\ddagger}$

\begin{tabular}{|c|c|c|c|c|}
\hline \multirow[t]{3}{*}{ Variable } & Slope & (Std. Err.) & Slope & (Std. Err.) \\
\hline & \multicolumn{2}{|c|}{ France } & \multicolumn{2}{|c|}{ The Netherlands } \\
\hline & \multicolumn{4}{|c|}{ Innovation occurrence $_{t}$} \\
\hline Innovation occurrence $e_{t-1}$ & 0.059 & $(0.038)$ & 0.011 & $(0.070)$ \\
\hline Innovation occurrence $0_{i}, 3$ waves & $0.067^{\dagger}$ & $(0.040)$ & $0.293^{* *}$ & $(0.077)$ \\
\hline Innovation occurrence $_{0_{i}}, 2$ waves & $0.134^{* *}$ & $(0.025)$ & $0.285^{* *}$ & $(0.046)$ \\
\hline$(\text { Sales/employee })_{t-1}$, in log & 0.001 & $(0.007)$ & 0.003 & $(0.010)$ \\
\hline$(\mathrm{R} \& \mathrm{D} / \text { employee })_{t-1}$, in log & 0.009 & $(0.011)$ & $0.069^{* *}$ & $(0.018)$ \\
\hline$\left(D_{\text {non-continuous }} R \& D\right)_{t-1}$ & $-0.213^{* *}$ & $(0.027)$ & $-0.241^{* *}$ & $(0.038)$ \\
\hline \multicolumn{5}{|l|}{ Size class } \\
\hline $\mathrm{D}_{\#}$ employees $\leq 50$ & $-0.198^{* *}$ & $(0.049)$ & $-0.129^{\dagger}$ & $(0.069)$ \\
\hline $\mathrm{D}_{50<\# \text { employees } \leq 250}$ & $-0.138^{* *}$ & $(0.035)$ & -0.040 & $(0.059)$ \\
\hline 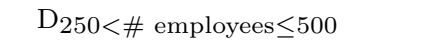 & -0.043 & $(0.030)$ & 0.089 & $(0.074)$ \\
\hline \multirow[t]{2}{*}{ Market share $t_{-1}$, in log } & $0.027^{* *}$ & $(0.009)$ & $0.028^{*}$ & $(0.012)$ \\
\hline & \multicolumn{4}{|c|}{ Share of innovative sales $t$, in logit } \\
\hline Share of innov. sales $t-1$, in logit & $0.138^{* *}$ & $(0.048)$ & 0.055 & $(0.043)$ \\
\hline Share of innov. sales ${ }_{0_{i}}, 3$ waves & 0.044 & $(0.043)$ & $0.113^{* *}$ & $(0.040)$ \\
\hline Share of innov. sales $_{0_{i}}, 2$ waves & $0.191^{* *}$ & $(0.026)$ & $0.169^{* *}$ & $(0.030)$ \\
\hline$(\text { Sales/employee })_{t-1}$, in log & 0.002 & $(0.038)$ & -0.001 & $(0.039)$ \\
\hline$(\mathrm{R} \& \mathrm{D} / \text { employee })_{t-1}$, in log & $0.067^{\dagger}$ & $(0.035)$ & $0.129^{* *}$ & $(0.032)$ \\
\hline$\left(\mathrm{D}_{\text {non-continuous } \mathrm{R} \& \mathrm{D}}\right)_{t-1}$ & $-0.230^{* *}$ & $(0.009)$ & $-0.249^{* *}$ & $(0.042)$ \\
\hline \multicolumn{5}{|l|}{ Size class } \\
\hline $\mathrm{D}_{\#}$ employees $\leq 50$ & 0.546 & $(0.520)$ & 0.436 & $(0.333)$ \\
\hline 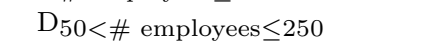 & 0.142 & $(0.149)$ & 0.275 & $(0.192)$ \\
\hline 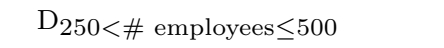 & 0.263 & $(0.255)$ & 0.088 & $(0.232)$ \\
\hline \multirow[t]{2}{*}{ Market share $_{t-1}$, in $\log$} & $0.079^{* *}$ & $(0.005)$ & $0.048^{*}$ & $(0.023)$ \\
\hline & \multicolumn{4}{|c|}{ Labor productivityt: sales/employee, in log } \\
\hline$(\text { Sales/employee })_{t-1}$, in log & $0.527^{* *}$ & $(0.056)$ & $0.320^{* *}$ & $(0.066)$ \\
\hline$(\text { Sales/employee })_{0_{i}}, 3$ waves & $0.337^{* *}$ & $(0.056)$ & $0.282^{* *}$ & $(0.066)$ \\
\hline$(\text { Sales/employee })_{0_{i}}, 2$ waves & $0.852^{* *}$ & $(0.012)$ & $0.583^{* *}$ & $(0.024)$ \\
\hline Latent share of innovative sales $t$ & $0.049^{* *}$ & $(0.011)$ & $0.099^{* *}$ & $(0.026)$ \\
\hline (Investment/employee $)_{t}$, in log & $0.065^{* *}$ & $(0.006)$ & $0.120^{* *}$ & $(0.012)$ \\
\hline \multirow[t]{2}{*}{ Employment $_{t}$, in log } & $-0.025^{* *}$ & $(0.008)$ & $-0.070^{* *}$ & $(0.017)$ \\
\hline & \multicolumn{4}{|c|}{ Covariance matrix } \\
\hline \multicolumn{5}{|l|}{ Individual effects } \\
\hline$\sigma_{a_{1}}$ & $0.322^{* *}$ & $(0.092)$ & $0.492^{* *}$ & $(0.134)$ \\
\hline$\sigma_{a_{2}}$ & $0.673^{* *}$ & $(0.190)$ & $0.642^{* *}$ & $(0.213)$ \\
\hline$\sigma_{a_{3}}$ & $0.095^{* *}$ & $(0.026)$ & $0.158^{* *}$ & $(0.060)$ \\
\hline$\rho_{a_{1} a_{2}}$ & $0.546^{* *}$ & $(0.128)$ & $0.544^{* *}$ & $(0.146)$ \\
\hline$\rho_{a_{1} a_{3}}$ & -0.094 & $(0.315)$ & -0.121 & $(0.350)$ \\
\hline$\rho_{a_{2} a_{3}}$ & -0.108 & $(0.302)$ & -0.151 & $(0.362)$ \\
\hline \multicolumn{5}{|l|}{ Idiosyncratic errors } \\
\hline$\sigma_{\varepsilon_{2}}$ & $2.481^{* *}$ & $(0.075)$ & $1.791^{* *}$ & $(0.098)$ \\
\hline$\sigma_{\varepsilon_{3}}$ & $0.320^{* *}$ & $(0.011)$ & $0.596^{* *}$ & $(0.021)$ \\
\hline$\rho_{\varepsilon_{1} \varepsilon_{2}}$ & \multicolumn{2}{|c|}{0.99 , fixed after grid search } & \multicolumn{2}{|c|}{0.95 , fixed after grid search } \\
\hline$\rho_{\varepsilon_{1} \varepsilon_{3}}$ & $-0.298^{* *}$ & $(0.077)$ & $-0.266^{* *}$ & $(0.074)$ \\
\hline$\rho_{\varepsilon_{2} \varepsilon_{3}}$ & $-0.301^{* *}$ & $(0.075)$ & $-0.288^{* *}$ & $(0.073)$ \\
\hline \# observations & \multicolumn{2}{|c|}{2505} & \multicolumn{2}{|c|}{1639} \\
\hline Log-likelihood & \multicolumn{2}{|c|}{-5045.613} & \multicolumn{2}{|c|}{-3922.326} \\
\hline
\end{tabular}


Table 6: FIML estimates of the model with observed innovation indicator to explain productivity: Unbalanced panel data samples from Dutch and French CIS 2, CIS 3 and CIS $4^{\ddagger}$

\begin{tabular}{|c|c|c|c|c|}
\hline \multirow[t]{3}{*}{ Variable } & Slope & Std. Err.) & Slope & (Std. Err.) \\
\hline & \multicolumn{2}{|c|}{ France } & \multicolumn{2}{|c|}{ The Netherlands } \\
\hline & \multicolumn{4}{|c|}{ Innovation occurrence $_{t}$} \\
\hline Innovation occurrence $e_{t-1}$ & 0.057 & $(0.041)$ & 0.004 & $(0.072)$ \\
\hline Innovation occurrence $0_{i}, 3$ waves & 0.073 & $(0.046)$ & $0.304^{* *}$ & $(0.079)$ \\
\hline Innovation occurrence $0_{i}, 2$ waves & $0.134^{* *}$ & $(0.026)$ & $0.292^{* *}$ & $(0.046)$ \\
\hline$(\text { Sales } / \text { employee })_{t-1}$, in log & 0.001 & $(0.007)$ & 0.004 & $(0.010)$ \\
\hline$(\mathrm{R} \& \mathrm{D} / \mathrm{employee})_{t-1}$, in $\log$ & 0.011 & $(0.012)$ & $0.070^{* *}$ & $(0.019)$ \\
\hline$\left(D_{\text {non-continuous }} \mathrm{R} \& \mathrm{D}\right)_{t-1}$ & $-0.222^{* *}$ & $(0.027)$ & $-0.246^{* *}$ & $(0.038)$ \\
\hline \multicolumn{5}{|l|}{ Size class } \\
\hline $\mathrm{D}_{\#}$ employees $\leq 50$ & $-0.227^{* *}$ & $(0.050)$ & $-0.128^{\dagger}$ & $(0.069)$ \\
\hline $\mathrm{D}_{50<\# \text { employees } \leq 250}$ & $-0.142^{* *}$ & $(0.038)$ & -0.045 & $(0.059)$ \\
\hline 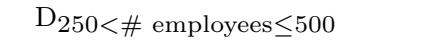 & -0.041 & $(0.031)$ & 0.079 & $(0.075)$ \\
\hline \multirow[t]{2}{*}{ Market share $_{t-1}$, in log } & $0.021^{*}$ & $(0.010)$ & $0.027^{*}$ & $(0.012)$ \\
\hline & \multicolumn{4}{|c|}{ Share of innovative sales $_{t}$, in logit } \\
\hline Share of innov. sales $t-1$, in logit & $0.110^{*}$ & $(0.049)$ & 0.036 & $(0.044)$ \\
\hline Share of innov. sales $_{0_{i}}, 3$ waves & 0.060 & $(0.045)$ & $0.141^{* *}$ & $(0.040)$ \\
\hline Share of innov. sales $_{i}, 2$ waves & $0.181^{* *}$ & $(0.027)$ & $0.173^{* *}$ & $(0.030)$ \\
\hline$(\text { Sales/employee })_{t-1}$, in $\log$ & 0.002 & $(0.037)$ & 0.001 & $(0.029)$ \\
\hline$(\mathrm{R} \& \mathrm{D} / \mathrm{employee})_{t-1}$, in $\log$ & $0.068^{\dagger}$ & $(0.035)$ & $0.126^{* *}$ & $(0.031)$ \\
\hline ( $\left.\mathrm{D}_{\text {non-continuous } \mathrm{R} \& \mathrm{D}}\right)_{t-1}$ & $-0.314^{* *}$ & $(0.011)$ & $-0.254^{* *}$ & $(0.043)$ \\
\hline \multicolumn{5}{|l|}{ Size class } \\
\hline $\mathrm{D}_{\#}$ employees $\leq 50$ & 0.319 & $(0.227)$ & 0.309 & $(0.235)$ \\
\hline $\mathrm{D}_{50}<\#$ employees $\leq 250$ & 0.157 & $(0.161)$ & 0.123 & $(0.192)$ \\
\hline 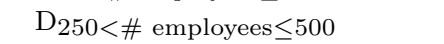 & 0.259 & $(0.224)$ & -0.139 & $(0.233)$ \\
\hline \multirow[t]{2}{*}{ Market share $t-1$, in log } & $0.056^{*}$ & $(0.022)$ & $0.040^{\dagger}$ & $(0.021)$ \\
\hline & \multicolumn{4}{|c|}{ Labor productivity $t$ : sales/employee, in log } \\
\hline$(\text { Sales/employee })_{t-1}$, in $\log$ & $0.532^{* *}$ & $(0.056)$ & $0.330^{* *}$ & $(0.066)$ \\
\hline$(\text { Sales/employee })_{0_{i}}, 3$ waves & $0.341^{* *}$ & $(0.056)$ & $0.282^{* *}$ & $(0.066)$ \\
\hline$(\text { Sales/employee })_{0_{i}}, 2$ waves & $0.861^{* *}$ & $(0.012)$ & $0.594^{* *}$ & $(0.023)$ \\
\hline Observed innovation indicator $t$ & 0.056 & $(0.042)$ & $0.197^{* *}$ & $(0.059)$ \\
\hline (Investment/employee $)_{t}$, in $\log$ & $0.065^{* *}$ & $(0.006)$ & $0.121^{* *}$ & $(0.012)$ \\
\hline \multirow[t]{2}{*}{ Employment $_{t}$, in $\log$} & -0.012 & $(0.007)$ & $-0.064^{* *}$ & $(0.016)$ \\
\hline & \multicolumn{4}{|c|}{ Covariance matrix } \\
\hline \multicolumn{5}{|l|}{ Individual effects } \\
\hline$\sigma_{a_{1}}$ & 0.284 & $(0.177)$ & $0.492^{* *}$ & $(0.143)$ \\
\hline$\sigma_{a_{2}}$ & $0.757^{* *}$ & $(0.150)$ & $0.710^{* *}$ & $(0.185)$ \\
\hline$\sigma_{a_{3}}$ & $0.094^{* *}$ & $(0.025)$ & $0.154^{* *}$ & $(0.058)$ \\
\hline$\rho_{a_{1} a_{2}}$ & $0.535^{* *}$ & $(0.170)$ & $0.527^{* *}$ & $(0.148)$ \\
\hline$\rho_{a_{1} a_{3}}$ & 0.242 & $(0.362)$ & 0.055 & $(0.365)$ \\
\hline$\rho_{a_{2} a_{3}}$ & 0.271 & $(0.314)$ & 0.224 & $(0.329)$ \\
\hline \multicolumn{5}{|l|}{ Idiosyncratic errors } \\
\hline$\sigma_{\varepsilon_{2}}$ & $2.463^{* *}$ & $(0.083)$ & $1.758^{* *}$ & $(0.096)$ \\
\hline$\sigma_{\varepsilon_{3}}$ & $0.308^{* *}$ & $(0.008)$ & $0.580^{* *}$ & $(0.018)$ \\
\hline$\rho_{\varepsilon_{1} \varepsilon_{2}}$ & \multicolumn{2}{|c|}{0.99, fixed after grid search } & \multicolumn{2}{|c|}{0.95 , fixed after grid search } \\
\hline$\rho_{\varepsilon_{1} \varepsilon_{3}}^{\varepsilon_{1} \varepsilon_{2}}$ & -0.071 & $(0.114)$ & $-0.223^{* *}$ & $(0.072)$ \\
\hline$\rho_{\varepsilon_{2} \varepsilon_{3}}$ & -0.024 & $(0.043)$ & $-0.128^{*}$ & $(0.052)$ \\
\hline \# observations & \multicolumn{2}{|c|}{2505} & \multicolumn{2}{|c|}{1639} \\
\hline Log-likelihood & \multicolumn{2}{|c|}{-5054.238} & \multicolumn{2}{|c|}{-3925.706} \\
\hline
\end{tabular}


Table 7: FIML estimates of the model with observed innovation intensity to explain productivity: Unbalanced panel data samples from Dutch and French CIS 2, CIS 3 and CIS $4^{\ddagger}$

\begin{tabular}{|c|c|c|c|c|}
\hline \multirow[t]{3}{*}{ Variable } & Slope & (Std. Err.) & Slope & (Std. Err.) \\
\hline & \multicolumn{2}{|c|}{ France } & \multicolumn{2}{|c|}{ The Netherlands } \\
\hline & \multicolumn{4}{|c|}{ Innovation occurrence $t_{t}$} \\
\hline Innovation occurrence $_{t-1}$ & $0.095^{* *}$ & $(0.034)$ & 0.006 & $(0.070)$ \\
\hline Innovation occurrence $_{0_{i}}, 3$ waves & 0.044 & $(0.035)$ & $0.302^{* *}$ & $(0.077)$ \\
\hline Innovation occurrence $_{0_{i}}, 2$ waves & $0.133^{* *}$ & $(0.024)$ & $0.292^{* *}$ & $(0.046)$ \\
\hline$(\text { Sales/employee })_{t-1}$, in log & 0.000 & $(0.006)$ & 0.003 & $(0.010)$ \\
\hline$(\mathrm{R} \& \mathrm{D} / \text { employee })_{t-1}$, in log & 0.008 & $(0.010)$ & $0.070^{* *}$ & $(0.019)$ \\
\hline$\left(D_{\text {non-continuous }} \& \mathrm{D}\right)_{t-1}$ & $-0.169^{* *}$ & $(0.025)$ & $-0.241^{* *}$ & $(0.038)$ \\
\hline \multicolumn{5}{|l|}{ Size class } \\
\hline $\mathrm{D}_{\#}$ employees $\leq 50$ & $-0.200^{* *}$ & $(0.045)$ & $-0.127^{\dagger}$ & $(0.069)$ \\
\hline 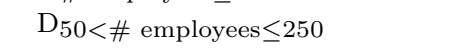 & $-0.138^{* *}$ & $(0.032)$ & -0.041 & $(0.059)$ \\
\hline $\mathrm{D}_{250<\# \text { employees } \leq 500}$ & $-0.050^{\dagger}$ & $(0.069)$ & 0.087 & $(0.074)$ \\
\hline \multirow[t]{2}{*}{ Market share $t-1$, in log $^{-}$} & $0.027^{* *}$ & $(0.021)$ & $0.028^{*}$ & $(0.011)$ \\
\hline & \multicolumn{4}{|c|}{ Share of innovative sales $t$, in logit } \\
\hline Share of innov. sales $t-1$, in logit & $0.139^{* *}$ & $(0.041)$ & 0.044 & $(0.044)$ \\
\hline Share of innov. sales $0_{i}, 3$ waves & 0.030 & $(0.036)$ & $0.130^{* *}$ & $(0.040)$ \\
\hline Share of innov. sales $0_{i}, 2$ waves & $0.177^{* *}$ & $(0.026)$ & $0.172^{* *}$ & $(0.030)$ \\
\hline$(\text { Sales/employee })_{t-1}$, in log & 0.003 & $(0.034)$ & -0.009 & $(0.039)$ \\
\hline$(\mathrm{R} \& \mathrm{D} / \text { employee })_{t-1}$, in log & $0.049^{\dagger}$ & $(0.025)$ & $0.130^{* *}$ & $(0.032)$ \\
\hline$\left(D_{\text {non-continuous }} \& \&\right)_{t-1}$ & $-0.199^{* *}$ & $(0.009)$ & $-0.250^{* *}$ & $(0.041)$ \\
\hline \multicolumn{5}{|l|}{ Size class } \\
\hline $\mathrm{D}_{\#}$ employees $\leq 50$ & 0.492 & $(0.405)$ & 0.363 & $(0.234)$ \\
\hline 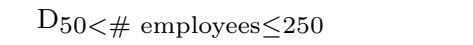 & 0.095 & $(0.135)$ & 0.177 & $(0.191)$ \\
\hline $\mathrm{D}_{250<\# \text { employees } \leq 500}$ & 0.177 & $(0.112)$ & -0.052 & $(0.233)$ \\
\hline \multirow[t]{2}{*}{ Market share $_{t-1}$, in log } & $0.096^{* *}$ & $(0.036)$ & $0.047^{*}$ & $(0.023)$ \\
\hline & \multicolumn{4}{|c|}{ Labor productivity ${ }_{t}$ : sales/employee, in log } \\
\hline$(\text { Sales/employee })_{t-1}$, in log & $0.420^{* *}$ & $(0.054)$ & $0.324^{* *}$ & $(0.067)$ \\
\hline$(\text { Sales/employee })_{0_{i}}, 3$ waves & $0.427^{* *}$ & $(0.053)$ & $0.285^{* *}$ & $(0.067)$ \\
\hline$(\text { Sales/employee })_{0_{i}}, 2$ waves & $0.836^{* *}$ & $(0.012)$ & $0.590^{* *}$ & $(0.023)$ \\
\hline Observed share of innovative sales $t$ & $0.122^{* *}$ & $(0.010)$ & $0.054^{* *}$ & $(0.014)$ \\
\hline$(\text { Investment/employee })_{t}$, in $\log$ & $0.066^{* *}$ & $(0.006)$ & $0.120^{* *}$ & $(0.012)$ \\
\hline \multirow[t]{2}{*}{ Employment $_{t}$, in log } & $-0.037^{* *}$ & $(0.007)$ & $-0.071^{* *}$ & $(0.017)$ \\
\hline & \multicolumn{4}{|c|}{ Covariance matrix } \\
\hline \multicolumn{5}{|l|}{ Individual effects } \\
\hline$\sigma_{a_{1}}$ & 0.154 & $(0.106)$ & $0.494^{* *}$ & $(0.132)$ \\
\hline$\sigma_{a_{2}}$ & $0.511^{* *}$ & $(0.140)$ & $0.649^{* *}$ & $(0.207)$ \\
\hline$\sigma_{a_{3}}$ & $0.133^{* *}$ & $(0.019)$ & $0.157^{* *}$ & $(0.060)$ \\
\hline$\rho_{a_{1} a_{2}}$ & $0.557^{* *}$ & $(0.124)$ & $0.550^{* *}$ & $(0.139)$ \\
\hline$\rho_{a_{1} a_{3}}$ & 0.011 & $(0.230)$ & -0.002 & $(0.361)$ \\
\hline$\rho_{a_{2} a_{3}}$ & 0.117 & $(0.195)$ & 0.120 & $(0.382)$ \\
\hline \multicolumn{5}{|l|}{ Idiosyncratic errors } \\
\hline$\sigma_{\varepsilon_{2}}$ & $2.459^{* *}$ & $(0.065)$ & $1.795^{* *}$ & $(0.098)$ \\
\hline$\sigma_{\varepsilon_{3}}$ & $0.357^{* *}$ & $(0.012)$ & $0.586^{* *}$ & $(0.019)$ \\
\hline$\rho_{\varepsilon_{1} \varepsilon_{2}}$ & \multicolumn{2}{|c|}{ 0.99, fixed after grid search } & \multicolumn{2}{|c|}{0.95 , fixed after grid search } \\
\hline$\rho_{\varepsilon_{1} \varepsilon_{3}}$ & $-0.570^{* *}$ & $(0.042)$ & $-0.274^{* *}$ & $(0.076)$ \\
\hline$\rho_{\varepsilon_{2} \varepsilon_{3}}$ & $-0.691^{* *}$ & $(0.038)$ & $-0.259^{* *}$ & $(0.069)$ \\
\hline \# observations & \multicolumn{2}{|c|}{2505} & \multicolumn{2}{|c|}{1639} \\
\hline Log-likelihood & \multicolumn{2}{|c|}{-5021.290} & \multicolumn{2}{|c|}{-3923.897} \\
\hline
\end{tabular}




\subsection{Determinants of innovation and productivity}

It is first of all remarkable and comforting to notice that the results are quite consistent and robust across specifications. We shall return to this finding in the next subsection. For now, let us take advantage of it by commenting jointly on the results from the four specifications.

Tables 4 to 7 show that large firms are more likely to be product innovators in France while no such evidence is found for Dutch manufacturing. ${ }^{16}$ Size does not significantly affect the innovation intensities among innovators, a typical result mentioned in Mairesse and Mohnen (2010). A doubling of the very low average market share from $1.5 \%$ to $3 \%$ is associated to a 3 percentage point higher propensity to innovate in products and a 4 to 10 percent higher share in total sales due to new products. ${ }^{17}$

Overall we find evidence of a lagged impact of R\&D on innovation. Both in France and in The Netherlands, enterprises that declare undertaking R\&D continuously during the previous two to four years are more likely to be product innovators and attain a larger share of innovative sales. The effect of a higher intensity of R\&D on present innovation is stronger and more significant in The Netherlands than in France. The estimates show that Dutch firms with a $1 \%$ higher R\&D intensity four years earlier show a $7 \%$ higher probability of being a product innovator today, and a $0.13 \%$ higher share of innovative sales. The estimates are lower for France where a $1 \%$ increase in R\&D intensity four years earlier does not significantly affect the probability to innovate, although it corresponds to an increase in the share of innovative sales of about $0.7 \%$ (and significant at the $10 \%$ level)..$^{18}$

The estimated output elasticities of labor and physical capital are all statistically significant and their orders of magnitude are not unreasonable. The coefficient of the log of employment reveals that the scale elasticity is around 0.97 in France and around 0.93 in The Netherlands, pointing to slightly decreasing returns to scale. If we subtract the estimated capital elasticity (0.065 for France and 0.120 for The Netherlands) and assume an output elasticity of materials of $0.5,{ }^{19}$ we obtain an output elasticity of labor of around 0.40 in France and 0.31 in The Netherlands. ${ }^{20}$

\footnotetext{
${ }^{16}$ Since the reference size category consists of firms with more than 500 employees, the negative signs for the other categories indicate a positive size effect.

17 The marginal effects on the probability of the average firm to become a product innovator, reported in Tables 4-7, are obtained in the usual way, (see Greene, 2011, page 689). Similarly, the marginal effects in the equation of the share of innovative sales are given by derivating $E\left(y_{2 i t} \mid y_{1 i t}=1\right)$. The expression of this conditional expectation is given in Greene (2011, page 873).

${ }^{18}$ To have a better appreciation of the time span between R\&D investment and innovation success, we would of course need a longer and yearly panel allowing us to estimate a distributed lag model, along the lines for example of Pakes and Griliches (1980) and Hall et al. (1986) as regards R\&D and patents.

${ }^{19}$ Assuming that materials account for half of the value of output growth and are priced at their marginal productivity, we approximate the output elasticity of materials at 0.5. Unfortunately, we do not have data on materials to estimate their output elasticity.

${ }^{20}$ If the capital stock follows the perpetual inventory formula and its growth rate $(g)$ is constant over time, then it can be shown that $\log \left(I_{t}\right)=\log [1-(1-\delta) /(1+g)]+\log \left(K_{t}\right)$. The estimated investment elasticity would then not be very different from the estimated capital stock elasticity.
} 


\subsection{The effects of innovation output on labor productivity}

Table 8 compares the four sets of elasticities and semi-elasticities of labor productivity with respect to innovation from Tables 4 to 7, testing on the one hand their equality in the two countries for each specification, and on the other hand the equivalence of the latent and observed model specifications. To be more precise we test whether the models with latent and observed innovation output in the labor productivity equation are equally close to the 'true' unknown model. All these elasticities are positive and highly statistically significant except in the case of the observed innovation indicator for France.

To be more precise we can make the following remarks. Firstly, these estimates are statistically different in the two countries only in the specification with observed innovation. A product innovator has on average a $20 \%$ higher labor productivity than a non-innovator in Dutch manufacturing and a 6\% higher labor productivity in French manufacturing. By contrast, in French manufacturing a $1 \%$ increase in the share of innovative sales raises labor productivity on average by $0.12 \%$, compared to $0.05 \%$ in Dutch manufacturing. Labor productivity is more responsive to increases in product innovation in French than in Dutch manufacturing enterprises.

Secondly, using Vuong's (1989) LR test for non-nested hypotheses, we conclude that the models, with respectively latent and observed innovation output in the labor productivity equation, are equally close to the 'true' unknown model. This result contrasts with that for France by Duguet (2006) who used a similar test by Davidson and MacKinnon (1981) to conclude that observed innovation is a better predictor of TFP growth than latent innovation. A likely reason for the difference may be that the two-step estimation procedure used by Duguet (2006) ignores the correlation between the errors in the innovation and productivity equations. In our case, there may be little difference between the latent and observed innovation output specification because the modeling of the endogeneity of innovation on the basis of a latent variable is in any case contained in the combined likelihood function, whether we use latent or observed innovation indicators in the productivity equation. As for the similarity in the results when using a dichotomous or a continuous measure of innovation, the explanation could reside in the fact that, with the exception of the lagged dependent variables and the initial values, we use the same explanatory variables in both equations. However, in the absence of a full-fledged theoretical model, there is no reason why these explanatory variables should be different as identification of the parameters is already guaranteed by the inclusion of the lagged dependent variables and the initial conditions that are different in both equations. ${ }^{21}$

\footnotetext{
${ }^{21}$ Löö (2005) proposes a set of variables that can potentially be used to explain differently the occurrence of product innovation and the innovation intensity. These variables, however, are not available in all three waves of the data for both countries (e.g. human capital, location of main customers) or are only available for innovative firms
} 
We corroborate the finding of Mairesse et al. (2005) that the estimates of innovation output in the productivity equation are significant only when the endogeneity of innovation is properly taken into account. For instance, when innovation is treated as exogenous in the productivity equation, the semi-elasticity of labor productivity with respect to innovation occurrence drops from $20 \%$ to $4 \%$ and becomes statistically insignificant in Dutch manufacturing, and the elasticity of labor productivity with respect to the observed share of innovative sales decreases from $0.12 \%$ to $0.01 \%$ in French manufacturing (results not tabulated but available upon request). In our analysis, the endogeneity of innovation output in the labor productivity equation operates in both types of models largely through the covariance matrices of the individual effects and the idiosyncratic errors. The correlations between innovation output and labor productivity, $\rho_{\varepsilon_{1} \varepsilon_{3}}$ and $\rho_{\varepsilon_{2} \varepsilon_{3}}$, being in general statistically significant, the null hypothesis of exogeneity of the innovation output regressor in the labor productivity equation is clearly rejected at any conventional significance level using a Wald or an LR test.

Table 8: Labor productivity elasticities and semi-elasticities of innovation output ${ }^{\dagger}$

\begin{tabular}{|c|c|c|c|c|c|c|}
\hline \multirow[t]{3}{*}{ I) Measures of innovation output } & \multicolumn{2}{|c|}{ France } & \multicolumn{2}{|c|}{ The Netherlands } & \multicolumn{2}{|c|}{ Test of equality } \\
\hline & Slope & (Std. Err.) & Slope & (Std. Err.) & $|z|$ & $\mathrm{p}$-value \\
\hline & \multicolumn{6}{|c|}{ Latent innovation to explain labor productivity } \\
\hline 1) Latent innovation propensity & $0.074^{* *}$ & $(0.020)$ & $0.121^{* *}$ & $(0.029)$ & 1.316 & 0.188 \\
\hline \multirow[t]{2}{*}{ 2) Latent share of innov. sales } & $0.049^{* *}$ & $(0.011)$ & $0.099^{* *}$ & $(0.026)$ & 1.800 & 0.072 \\
\hline & \multicolumn{6}{|c|}{ Observed innovation to explain labor productivity } \\
\hline 1) Observed innovation indicator & 0.056 & $(0.042)$ & $0.197^{* *}$ & $(0.059)$ & $1.956^{*}$ & 0.050 \\
\hline 2) Observed share of innov. sales & $0.122^{* *}$ & $(0.010)$ & $0.054^{* *}$ & $(0.014)$ & $3.993^{* *}$ & 0.000 \\
\hline \multirow[t]{2}{*}{ II) Vuong's LR test } & \multicolumn{3}{|c|}{ France } & \multicolumn{3}{|c|}{ The Netherlands } \\
\hline & \multicolumn{2}{|r|}{$|z|$} & $\mathrm{p}$-value & $|\mathrm{z}|$ & \multicolumn{2}{|c|}{$\mathrm{p}$-value } \\
\hline Latent 1) vs observed 1) & \multicolumn{2}{|r|}{1.252} & 0.211 & 1.391 & \multicolumn{2}{|c|}{0.164} \\
\hline Latent 2) vs observed 2) & \multicolumn{2}{|r|}{0.838} & 0.402 & 0.323 & \multicolumn{2}{|c|}{0.746} \\
\hline \multicolumn{7}{|c|}{$\begin{array}{l}\left.{ }^{\dagger} \mathrm{I}\right) \text { The } \mathrm{z} \text {-statistic is computed as the ratio of the difference of the elasticities across countries, assuming inde- } \\
\text { pendence between them, over the standard error of that difference. II) The non-nested null hypothesis of the } \\
\text { test is } \mathrm{H}_{0} \text { : both models are as close to the 'true' model. The resulting z-statistic is computed as } z=\left[\ln l_{1}-\ln l_{2}\right. \\
\left.-\ln \text { obs }\left(k_{1}-k_{2}\right) / 2\right] /\left[\text { obs } \times \operatorname{var}\left(\ln l_{1 i}-\ln l_{2 i}\right)\right]^{\frac{1}{2}} \text {, where obs is the number of observations, } k_{j}(j=1,2) \text { the number of } \\
\text { parameters and } \operatorname{var}() \text { is the sample variance of the difference in the pointwise log-likelihoods of both models. }\end{array}$} \\
\hline
\end{tabular}

\subsection{Covariance matrix of residuals}

In order to capture enterprises' unobserved ability to be innovative and productive we account for individual effects in each equation of the model. Likelihood ratio (LR) tests reject the absence of individual effects at the $1 \%$ level of significance. ${ }^{22}$ The standard error for the individual effects explains at least one quarter of the total standard error in each equation. The correlation between (e.g. partnership in innovation activities).

${ }^{22}$ To save space, the results of the LR tests are not reported but can be obtained upon request. 
the unobserved individual effects in the innovation propensity and the innovation intensity equations is positive and rather high (around 0.5) as expected. Similar omitted variables explain the occurrence and the intensity of product innovation. The correlations between the idiosyncratic effects in the two equations after accounting for dynamics, common determinants and individual effects are so high that we have difficulties to estimate them precisely and are forced to fix their values at 0.99 for France and 0.95 for the Netherlands to avoid convergence problems in the iterative search for a maximum likelihood. There is no significant correlation between the individual effects in the productivity and the innovation equations. Instead, we observe a negative and statistically significant correlation, in both countries and in all specifications, between the idiosyncratic error terms in the innovation and the labor productivity equations. This phenomenon could be explained by a missing adjustment cost term: in order to innovate, enterprises may need to increase their personnel, which in the short run may lead to a decrease in labor productivity because of adjustment costs and time to learn.

\subsection{The dynamics of innovation and productivity}

Let us now turn to the central issues of the paper, namely the persistence of innovation and labor productivity and the direction of causality between innovation and productivity.

\section{Persistence in innovation}

In order to assess whether there is true persistence in innovation, as defined in the econometric literature on panel data, it is important to control for individual effects and initial conditions (Hsiao, 2003). In our case, given that our panels are unbalanced with two or three consecutive observations by firm, we have an additional difficulty of disentangling the effect of the lagged dependent variable and of the initial conditions. Indeed, the initial values of the dependent variable on which we must project the individual effects correspond to a two-period lag for enterprises that are present in all three periods but to a one period lag for those that are present in only two adjacent periods. For the latter, the lagged dependent variable is the same as the initial value and therefore the associated coefficient picks up the sum of the two effects. Without imposing this constraint, we notice that, as expected, the slope of the initial value for the 2 -wave unbalanced panel is practically equal to the sum of the initial value for the 3 -wave balanced panel and the one period lagged effect.

As can be seen in Tables 4 to 7 , our results show no evidence of true persistence in product innovation in Dutch manufacturing neither for the occurrence nor for the intensity of innovation. In other words, once individual effects and the occurrence and the intensity of innovation in the initial period are controlled for, achieving successful innovations and generating innovative sales 
are no longer time dependent in Dutch manufacturing. In contrast, in French manufacturing there is some evidence in support of the 'success breeds success' hypothesis. Nevertheless, the evidence remains weak as the one-period lagged innovation has less of an effect than innovation in the initial period. By way of comparison, Raymond et al. (2010) found evidence of true innovation persistence in Dutch manufacturing but over a different time span and only for enterprises operating in hightechnology sectors. True persistence in the occurrence of product or process innovation was found by Peters (2009) for German manufacturing and service firms and by Huergo and Moreno (2011) for Spanish manufacturing firms. The last two studies, however, only use binary variables on innovation. The major difference between these specifications and the present one is that none of the previous specifications estimates the innovation and the productivity equations simultaneously with a contemporaneous correlation between the corresponding error terms.

\section{Persistence in productivity}

For both countries we find very strong evidence of true persistence in labor productivity in all specifications. Even after controlling for individual effects and initial productivity, one period lagged productivity conditions current productivity. The fact that highly productive firms tend to remain productive and less productive firms remain less productive is normally taken up by the initial condition characterizing the individual effect. The lagged productivity term could reflect the influence of a slowly decreasing stock of knowledge, which is not explicitly modeled but shows up in the persistence of productivity (see Klette, 1996; Klette and Johansen, 1998; Lokshin et al., 2008). Part of the persistence of productivity could also reflect persistence in firm market power given that we have to rely on a revenue measure of productivity in the absence of firm level price information to deflate gross output. The differences of persistence in innovation and productivity could also be due to errors of specification in our models, such as large random errors in the innovation measures or important missing factors in the productivity equation, for example skills, management practices and organizational characteristics.

\section{Causality}

In both countries, there is clear evidence of a unidirectional causality running from innovation to labor productivity during the period that we examine. In other words, four-year lagged R\&D has a positive and significant effect on current innovation output which is positively and significantly affected by past innovation output and has a positive and significant effect on labor productivity. We also estimate variants of the CDM model where labor productivity (eqs. (2.5a)$(2.5 \mathrm{~b}))$ is explained by innovation output in period $t$ and $\mathrm{R} \& \mathrm{D}$ intensity in period $t-1$. While 
innovation output is significant in all specifications, the direct effect of $R \& D$ on labor productivity is insignificant. ${ }^{23}$ In contrast, the lagged feedback effect of labor productivity on innovation is not economically nor statistically significant. This result suggests that the most productive enterprises at period $t-1$ do not necessarily invest more in $\mathrm{R} \& \mathrm{D}$ at period $t .^{24}$ This finding of unidirectional causality seems to be new in the empirical literature. It is robust across the four specifications and for the two countries.

Furthermore, as can be seen from the estimates documented in Appendix D, enterprises that were four years earlier closer to the technological frontier, defined in terms of labor productivity, are not more successful in achieving innovations nor in attaining a larger share of innovative sales. This result confirms the absence of a feedback effect of labor productivity, more precisely efficiency, on innovation.

\section{Robustness analysis}

Table 9 presents the estimation results for the model with latent innovation propensity as a predictor of labor productivity and radical innovation (i.e. product new the market) as a measure of innovation output. Our results on the persistence of innovation and labor productivity and the direction of causality between innovation and productivity are confirmed in this specification. ${ }^{25}$

\section{Conclusion}

We have in this study examined whether French and Dutch manufacturing firms display persistence in innovation and productivity, whether innovation Granger causes productivity or whether the reverse holds, whether the dynamics in the R\&D-innovation-productivity relationship differs between French and Dutch manufacturing firms, and finally whether models with observed or latent, qualitative or quantitative, innovation indicators yield different estimation results. To do so, we have used unbalanced panels of French and Dutch manufacturing firms resulting from three waves of the respective Community Innovation Surveys. With few exceptions, the results we obtain are not very different for the two countries and are robust to various specifications of the innovationproductivity relationship. As in many related studies based on cross-sectional firm data, we find

\footnotetext{
${ }^{23}$ The estimation results of these variants are not reported but can be obtained upon request. We thank an anonymous referee for pointing this out.

${ }^{24}$ Estimation results from regressions explaining R\&D at period $t$ by productivity at period $t-1$ are not reported but can be obtained upon request.

${ }^{25}$ To save space, we do not report the estimation results for the model with radical innovation as a measure of innovation output and latent innovation intensity and observed innovation (indicator and intensity) as predictors of labor productivity. The results are similar to those of Table 9 and available upon request.

Some studies consider process innovation, product innovation or a combination to explain labor productivities. They usually face identification problems as product and process innovation are highly correlated (see for instance Hall et al., 2013).
} 
Table 9: FIML estimates of the model with radical product innovation and latent innovation propensity to explain productivity: Unbalanced panel data samples from Dutch and French CIS 2, CIS 3 and CIS $4^{\ddagger}$

\begin{tabular}{|c|c|c|c|c|}
\hline \multirow[t]{3}{*}{ Variable } & Slope & (Std. Err.) & Slope & (Std. Err.) \\
\hline & \multicolumn{2}{|c|}{ France } & \multicolumn{2}{|c|}{ The Netherlands } \\
\hline & \multicolumn{4}{|c|}{ Radical innovation occurrence $t$} \\
\hline Radical innovation occurrence $t-1$ & 0.048 & $(0.033)$ & 0.026 & $(0.058)$ \\
\hline Radical innovation occurrence $0_{i}, 3$ waves & $0.101^{* *}$ & $(0.033)$ & $0.180^{* *}$ & $(0.055)$ \\
\hline Radical innovation occurrence $_{0_{i}}, 2$ waves & $0.105^{* *}$ & $(0.029)$ & $0.216^{* *}$ & $(0.037)$ \\
\hline$(\text { Sales/employee })_{t-1}$, in log & 0.002 & $(0.006)$ & 0.003 & $(0.007)$ \\
\hline$(\mathrm{R} \& \mathrm{D} / \mathrm{employee})_{t-1}$, in $\log$ & $0.031^{* *}$ & $(0.010)$ & $0.070^{* *}$ & $(0.014)$ \\
\hline$\left(\mathrm{D}_{\text {non-continuous } \mathrm{R} \& \mathrm{D}}\right)_{t-1}$ & $-0.179^{* *}$ & $(0.025)$ & $-0.141^{* *}$ & $(0.027)$ \\
\hline \multicolumn{5}{|l|}{ Size class } \\
\hline $\mathrm{D}_{\#}$ employees $\leq 50$ & $-0.155^{* *}$ & $(0.050)$ & 0.030 & $(0.057)$ \\
\hline $\mathrm{D}_{50<\# \text { employees }<250}$ & $-0.113^{* *}$ & $(0.034)$ & 0.040 & $(0.048)$ \\
\hline $\mathrm{D}_{250<\# \text { employees } \leq 500}$ & -0.043 & $(0.029)$ & $0.153^{* *}$ & $(0.058)$ \\
\hline \multirow[t]{2}{*}{ Market share $t-1$, in $\log$} & $0.037^{* *}$ & $(0.009)$ & $0.041^{* *}$ & $(0.010)$ \\
\hline & \multicolumn{4}{|c|}{ Share of innovative sales $_{t}$ (radical innovation), in logit } \\
\hline Share of innov. sales $t-1$, in logit & 0.069 & $(0.045)$ & 0.028 & $(0.058)$ \\
\hline Share of innov. sales $0_{i}, 3$ waves & $0.176^{* *}$ & $(0.048)$ & $0.164^{* *}$ & $(0.051)$ \\
\hline Share of innov. sales $_{0_{i}}, 2$ waves & $0.246^{* *}$ & $(0.043)$ & $0.199^{* *}$ & $(0.037)$ \\
\hline$(\text { Sales/employee })_{t-1}$, in $\log$ & 0.022 & $(0.046)$ & -0.456 & $(0.057)$ \\
\hline$(\mathrm{R} \& \mathrm{D} / \mathrm{employee})_{t-1}$, in log & $0.044^{\dagger}$ & $(0.023)$ & $0.060^{*}$ & $(0.030)$ \\
\hline$\left(D_{\text {non-continuous }} \mathrm{R} \& \mathrm{D}\right)_{t-1}$ & $-0.141^{*}$ & $(0.049)$ & $-0.080^{*}$ & $(0.039)$ \\
\hline \multicolumn{5}{|l|}{ Size class } \\
\hline $\mathrm{D}_{\#}$ employees $\leq 50$ & 0.430 & $(0.248)$ & 0.315 & $(0.258)$ \\
\hline $\mathrm{D}_{50<\# \text { employees } \leq 250}$ & 0.057 & $(0.138)$ & 0.233 & $(0.209)$ \\
\hline $\mathrm{D}_{250<\# \text { employees } \leq 500}$ & 0.160 & $(0.111)$ & -0.377 & $(0.252)$ \\
\hline \multirow[t]{2}{*}{ Market share $t-1$, in log } & $0.246^{* *}$ & $(0.044)$ & $0.199^{* *}$ & $(0.037)$ \\
\hline & \multicolumn{4}{|c|}{ Labor productivity $t$ : sales/employee, in log } \\
\hline$(\text { Sales/employee })_{t-1}$, in log & $0.606^{* *}$ & $(0.041)$ & $0.312^{* *}$ & $(0.067)$ \\
\hline$(\text { Sales/employee })_{0_{i}}, 3$ waves & $0.261^{* *}$ & $(0.042)$ & $0.280^{* *}$ & $(0.067)$ \\
\hline$(\text { Sales/employee })_{0_{i}}, 2$ waves & $0.858^{* *}$ & $(0.012)$ & $0.573^{* *}$ & $(0.024)$ \\
\hline Latent innovation propensity $t$ & $0.064^{* *}$ & $(0.020)$ & $0.180^{* *}$ & $(0.038)$ \\
\hline (Investment/employee $)_{t}$, in log & $0.064^{* *}$ & $(0.006)$ & $0.118^{* *}$ & $(0.012)$ \\
\hline \multirow[t]{2}{*}{ Employment $_{t}$, in $\log$} & $-0.023^{* *}$ & $(0.008)$ & $-0.088^{* *}$ & $(0.018)$ \\
\hline & \multicolumn{4}{|c|}{ Covariance matrix } \\
\hline \multicolumn{5}{|l|}{ Individual effects } \\
\hline$\sigma_{a_{1}}$ & 0.176 & $(0.151)$ & $0.387^{*}$ & $(0.193)$ \\
\hline$\sigma_{a_{2}}$ & $0.764^{* *}$ & $(0.200)$ & $0.699^{*}$ & $(0.270)$ \\
\hline$\sigma_{a_{3}}$ & $0.114^{* *}$ & $(0.020)$ & $0.178^{* *}$ & $(0.057)$ \\
\hline$\rho_{a_{1} a_{2}}$ & $0.304^{* *}$ & $(0.155)$ & $0.331^{*}$ & $(0.148)$ \\
\hline$\rho_{a_{1} a_{3}}$ & -0.061 & $(0.357)$ & -0.155 & $(0.335)$ \\
\hline$\rho_{a_{2} a_{3}}$ & 0.113 & $(0.253)$ & -0.069 & $(0.448)$ \\
\hline \multicolumn{5}{|l|}{ Idiosyncratic errors } \\
\hline$\sigma_{\varepsilon_{2}}$ & $1.817^{* *}$ & $(0.068)$ & $1.638^{* *}$ & $(0.145)$ \\
\hline$\sigma_{\varepsilon_{3}}$ & 0.325 & $(0.006)$ & $0.597^{* *}$ & $(0.022)$ \\
\hline$\rho_{\varepsilon_{1} \varepsilon_{2}}$ & 0.99, fixe & er grid search & 0.95, fix & ter grid search \\
\hline$\rho_{\varepsilon_{1} \varepsilon_{3}}$ & $-0.177^{* *}$ & $(0.071)$ & $-0.292^{* *}$ & $(0.075)$ \\
\hline$\rho_{\varepsilon_{2} \varepsilon_{3}}$ & $-0.162^{* *}$ & $(0.071)$ & $-0.287^{*}$ & $(0.079)$ \\
\hline \# observations & \multicolumn{2}{|c|}{2505} & \multicolumn{2}{|c|}{1639} \\
\hline Log-likelihood & \multicolumn{2}{|c|}{-3923.032} & \multicolumn{2}{|c|}{-3267.536} \\
\hline
\end{tabular}

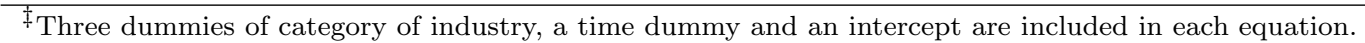

Significance levels : $\quad \dagger: 10 \% \quad *: 5 \% \quad * *: 1 \%$

that R\&D activities undertaken continuously during the previous two to four years, and the intensity of such activities, affect significantly the occurrence and the intensity of product innovations. 
We find weak, if any, evidence of persistence in product innovation, but strong evidence of persistence in labor productivity levels. Both the occurrence and the intensity of product innovation play an important role in enhancing firm labor productivity. Past productivity does not, however, affect product innovation significantly. Thus, our results provide evidence of a unidirectional causality running from innovation to productivity, without a feedback effect, and of a strong persistence in productivity but not in innovation. Our results are robust to different ways of modeling and estimating and hold for both countries.

In order to assess the generality of the result, it would be interesting to estimate the same model on more country data and longer periods, which will become possible with additional waves of innovation surveys in many countries. With the decision, at least in the European Union, to hold innovation surveys every two years, it would be worthwhile in the future to re-estimate this model with shorter lags (two years instead of four) and see whether the conclusions regarding the dynamics of innovation still hold. Productivity increases could also be due to process innovation. The introduction of process (and possibly other forms of) innovation would require one or more additional equations, a challenging but not impossible task. 


\section{Appendix A Numerical evaluation of the likelihood of the model with $y_{1 i t}^{*}$ or $y_{1 i t}$ as a predictor of labor productivity}

After obtaining the conditional likelihood functions shown in equations (3.13) and (3.14), the next step consists in deriving the unconditional counterparts to $l_{1 i \mid \underline{\boldsymbol{a}}_{i}}$ and $l_{2 i \mid \boldsymbol{a}_{i}}$, which are obtained by integrating out respectively $\underline{\boldsymbol{a}_{i}}$ and $\boldsymbol{a}_{i}$ with respect to their normal distribution. Formally,

$$
l_{1}=\prod_{i=1}^{N} \int_{a_{1 i}} \int_{a_{2 i}} \int_{\underline{a_{3 i}}} l_{1 i \mid \underline{\boldsymbol{a}_{i}}} h_{3}\left(a_{1 i}, a_{2 i}, \underline{a_{3 i}} \mid \ldots\right) d a_{1 i} d a_{2 i} d \underline{a_{3 i}}
$$

and

$$
l_{2}=\prod_{i=1}^{N} \int_{a_{1 i}} \int_{a_{2 i}} \int_{a_{3 i}} l_{2 i \mid \boldsymbol{a}_{i}} h_{3}\left(a_{1 i}, a_{2 i}, a_{3 i} \mid \ldots\right) d a_{1 i} d a_{2 i} d a_{3 i}
$$

Evidently, $l_{1}$ and $l_{2}$ cannot be derived analytically. Hence, we use Gauss-Hermite quadrature sequentially, along the lines of Raymond (2007), to evaluate the triple integrals. ${ }^{26}$ The GaussHermite quadrature states that

$$
\int_{-\infty}^{\infty} e^{-r^{2}} f(r) d r \simeq \sum_{m=1}^{M} w_{m} f\left(a_{m}\right)
$$

where $w_{m}$ and $a_{m}$ are respectively the weights and abscissae of the quadrature with $M$ being the total number of integration points. ${ }^{27}$ Numerical tables with values of $w_{m}$ and $a_{m}$ are formulated in mathematical textbooks (Abramowitz and Stegun, 1964). The larger $M$, the more accurate the approximation.

The trivariate normal density function of the structural form projection errors, $a_{1 i}, a_{2 i}$ and $a_{3 i}$, denoted by $h_{3}\left(a_{1 i}, a_{2 i}, a_{3 i} \mid \ldots\right)$, is written as

$$
h_{3}\left(a_{1 i}, a_{2 i}, a_{3 i} \mid \ldots\right)=\Gamma e^{\frac{-1}{2}\left(\Lambda_{11} \frac{a_{1 i}^{2}}{\sigma_{a_{1}}^{2}}+2 \Lambda_{12} \frac{a_{1 i}}{\sigma a_{1}} \frac{a_{2 i}}{\sigma a_{2}}+2 \Lambda_{13} \frac{a_{1 i}}{\sigma a_{1}} \frac{a_{3 i}}{\sigma a_{3}}+2 \Lambda_{23} \frac{a_{2 i}}{\sigma a_{2}} \frac{a_{3 i}}{\sigma a_{3}}+\Lambda_{22} \frac{a_{2 i}^{2}}{\sigma_{a_{2}}^{2}}+\Lambda_{33} \frac{a_{3 i}^{2}}{\sigma_{a_{3}}^{2}}\right)},
$$

where

$$
\Gamma=\left(\sigma_{a_{1}} \sigma_{a_{2}} \sigma_{a_{3}}\right)^{-1}(2 \pi)^{\frac{-3}{2}}(\Delta)^{\frac{-1}{2}}
$$

\footnotetext{
${ }^{26}$ The use of this numerical method is well documented in the econometric literature in the context of panel data single-equation models (see e.g. Butler and Moffitt, 1982; Rabe-Hesketh et al., 2005). However, its use in the context of panel data models with multiple equations remains to date limited. A few exceptions are Raymond (2007, chapter 3) who studies the performance of the method in two types of dynamic sample selection models, and Raymond et al. (2010) who apply the method to estimate the persistence of innovation incidence and innovation intensity.

${ }^{27}$ The abscissae of the quadrature, $a_{m}$, should not be confused with the projections errors $a_{1 i}, a_{2 i}$ and $a_{3 i}$.
} 
and the expressions of $\Delta$ and $\Lambda_{k l}\left(k, l=1,2,3 ; \Lambda_{k l}=\Lambda_{l k}\right)$ are given by

$$
\begin{aligned}
\Delta & =1-\rho_{a_{1} a_{2}}^{2}-\rho_{a_{1} a_{3}}^{2}-\rho_{a_{2} a_{3}}^{2}+2 \rho_{a_{1} a_{2}} \rho_{a_{1} a_{3}} \rho_{a_{2} a_{3}}, \\
\Lambda_{11} & =\frac{1-\rho_{a_{2} a_{3}}^{2}}{\Delta}, \Lambda_{12}=\frac{\rho_{a_{1} a_{3}} \rho_{a_{2} a_{3}}-\rho_{a_{1} a_{2}}}{\Delta}, \\
\Lambda_{22} & =\frac{1-\rho_{a_{1} a_{3}}^{2}}{\Delta}, \Lambda_{23}=\frac{\rho_{a_{1} a_{2}} \rho_{a_{1} a_{3}}-\rho_{a_{2} a_{3}}}{\Delta}, \\
\Lambda_{33} & =\frac{1-\rho_{a_{1} a_{2}}^{2}}{\Delta}, \Lambda_{13}=\frac{\rho_{a_{1} a_{2}} \rho_{a_{2} a_{3}}-\rho_{a_{1} a_{3}}}{\Delta} .
\end{aligned}
$$

The trivariate density expression of the reduced-form projection errors is written straightforwardly by replacing $a_{3 i}, \sigma_{a_{3}}, \rho_{a_{1} a_{3}}$ and $\rho_{a_{2} a_{3}}$ by their underlined counterparts to obtain the expressions of $\underline{\Delta}$ and $\underline{\Lambda_{k l}}\left(\underline{\Lambda_{k l}}=\underline{\Lambda_{l k}}\right)$.

Let us rewrite $l_{1}$ (eq. (A.1)) as

$$
l_{1}=\prod_{i=1}^{N} \int_{\underline{a_{3 i}}} G_{1}\left(\underline{a_{3 i}} \mid \ldots\right) \prod_{t=0_{i}+1}^{T_{i}} \frac{1}{\underline{\sigma_{\varepsilon_{3}}}} \phi_{1}\left(\frac{y_{3 i t}-A_{3 i t}-\gamma_{1} A_{1 i t}-\underline{a_{3 i}}}{\underline{\sigma_{\varepsilon_{3}}}}\right) H_{1}\left(\underline{a_{3 i}} \mid \ldots\right) d \underline{a_{3 i}},
$$

where $G_{1}\left(\underline{a_{3 i}} \mid \ldots\right)$ and $H_{1}\left(\underline{a_{3 i}} \mid \ldots\right)$ are functions of the sole projection error $\underline{a_{3 i}} . G_{1}\left(\underline{a_{3 i}} \mid \ldots\right)$ is derived from the trivariate density of the reduced-form projection errors and is equal to $e^{\frac{-1}{2}\left(\underline{\Lambda_{33}}\right.} \underline{a_{3 i}^{2}} \underline{\left.\sigma_{a_{3}}^{-2}\right)}$ with $\underline{\Lambda_{k l}}$ obtained from equation (A.6), and $H_{1}\left(\underline{a_{3 i}} \mid \ldots\right)$ is given by

$$
\begin{aligned}
H_{1}\left(\underline{a_{3 i}} \mid \ldots\right)= & \int_{a_{2 i}} G_{2}\left(a_{2 i}, \underline{a_{3 i}} \mid \ldots\right) \prod_{t=0_{i}+1}^{T_{i}}\left[\sigma_{\varepsilon_{2}}^{-1}\left(1-\underline{\rho_{\varepsilon_{2} \varepsilon_{3}}^{2}}\right)^{\frac{-1}{2}}\right] \\
& \phi_{1}\left(\frac{y_{2 i t}-A_{2 i t}-a_{2 i}-\frac{\rho_{\varepsilon_{2} \varepsilon_{3}} \sigma_{\varepsilon_{2}}}{\underline{\sigma_{\varepsilon_{3}}}}\left(y_{3 i t}-A_{3 i t}-\gamma_{1} A_{1 i t}-\underline{a_{3 i}}\right)}{\sigma_{\varepsilon_{2}} \sqrt{1-\underline{\rho_{\varepsilon_{2} \varepsilon_{3}}^{2}}}}\right) H_{2}\left(a_{2 i}, \underline{a_{3 i}} \mid \ldots\right) d a_{2 i} .
\end{aligned}
$$

$G_{2}\left(a_{2 i}, \underline{a_{3 i}} \mid \ldots\right)$ is also derived from the trivariate density of the reduced-form projection errors. It

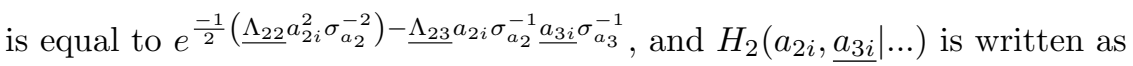

$$
\begin{aligned}
H_{2}\left(a_{2 i}, \underline{a_{3 i} \mid} \ldots\right)= & \int_{a_{1 i}} G_{3}\left(a_{1 i}, a_{2 i}, \underline{a_{3 i}} \mid \ldots\right) \prod_{t=0_{i}+1}^{T_{i}}\left[\Phi_{1}\left(\frac{-A_{1 i t}-a_{1 i}-\rho_{\varepsilon_{1} \varepsilon_{3}}}{\sqrt{\varepsilon_{3}}\left(y_{3 i t}-A_{3 i t}-\gamma_{1} A_{1 i t}-\underline{a_{3 i}}\right)}\right)\right]^{1-y_{1 i t}^{2}} \\
& {\left[\Phi_{1}\left(\frac{\left.A_{1 i t}+a_{1 i}+\underline{\rho_{12.3}} \sigma_{\varepsilon_{2}}^{-1}\left(y_{2 i t}-A_{2 i t}-a_{2 i}\right)+\underline{\rho_{13.2}} \underline{\sigma_{\varepsilon_{3}}^{-1}\left(y_{3 i t}\right.}-A_{3 i t}-\gamma_{1} A_{1 i t}-\underline{a_{3 i}}\right)}{\sqrt{1-\underline{R_{1.23}^{2}}}}\right)\right]^{y_{1 i t}} d a_{1 i}, }
\end{aligned}
$$

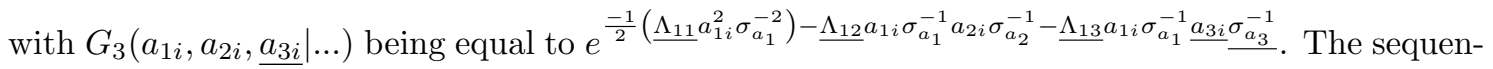
tial quadrature approach consists in approximating the single integral in equation (A.9) using the 
formula of equation (A.3) after making an appropriate variable change. Then, $H_{2}\left(a_{2 i}, \underline{a_{3 i}} \mid \ldots\right)$ is replaced by the resulting approximated expression into equation (A.8). A second approximation is carried out for the single integral of equation (A.8) using the same formula. We then plug the resulting expression of $H_{1}\left(\underline{\left.a_{3 i} \mid \ldots\right)}\right.$ into equation (A.7) and apply again the quadrature formula. The final expression of the unconditional likelihood, $l_{1}$, is then written as

$$
\begin{aligned}
& l_{1} \simeq \prod_{i=1}^{N} \underline{\Delta} \pi^{\frac{-3}{2}}\left[\left(1-\rho_{a_{1} a_{2}}^{2}\right)\left(1-\underline{\rho_{a_{1} a_{3}}^{2}}\right)\left(1-\underline{\rho_{a_{1} a_{2}}^{2}}\right)\right]^{\frac{-1}{2}} \sum_{m_{3}=1}^{M_{3}} w_{m_{3}} \prod_{t=0_{i}+1}^{T_{i}} \frac{1}{\sigma_{\varepsilon_{3}}} \phi_{1}\left(\frac{y_{3 i t}-A_{3 i t}-\gamma_{1} A_{1 i t}-a_{m_{3}}[\ldots]}{\underline{\sigma_{\varepsilon_{3}}}}\right) \\
& \sum_{m_{2}=1}^{M_{2}} w_{m_{2}} e^{\frac{-2 \Lambda_{23} a_{m_{2}} a_{m_{3}}}{\sqrt{\underline{\Lambda_{22}}} \frac{\Lambda_{33}}{n_{3}}}} \prod_{t=0_{i}+1}^{T_{i}}\left[\frac{1}{\sigma_{\varepsilon_{2}} \sqrt{1-\underline{\rho_{\varepsilon_{2} \varepsilon_{3}}^{2}}}} \phi_{1}\left(\frac{y_{2 i t}-A_{2 i t}-a_{m_{2}}[. . .]-\frac{\underline{\rho_{\varepsilon_{2} \varepsilon_{3}} \sigma_{\varepsilon_{2}}}}{\underline{\sigma_{\varepsilon_{3}}}}\left(y_{3 i t}-A_{3 i t}-\gamma_{1} A_{1 i t}-a_{m_{3}}[. .]\right)}{\sigma_{\varepsilon_{2}} \sqrt{1-\underline{\rho_{\varepsilon_{2} \varepsilon_{3}}^{2}}}}\right)\right]^{y_{1 i t}}
\end{aligned}
$$

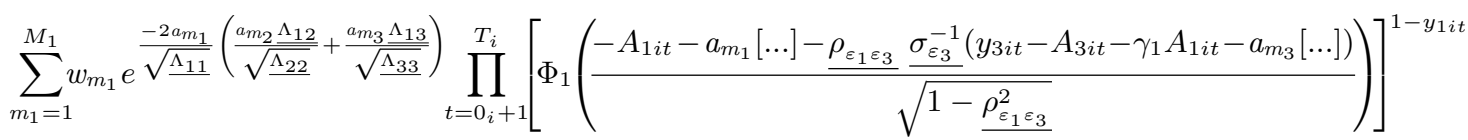

$$
\begin{aligned}
& {\left[\Phi_{1}\left(\frac{A_{1 i t}+a_{m_{1}}[\ldots]+\underline{\rho_{12.3}} \sigma_{\varepsilon_{2}}^{-1}\left(y_{2 i t}-A_{2 i t}-a_{m_{2}}[\ldots]\right)+\underline{\rho_{13.2}}}{\sqrt{1-\underline{R_{1.23}^{2}}}} \underline{\sigma_{\varepsilon_{3}}^{-1}\left(y_{3 i t}-A_{3 i t}-\gamma_{1} A_{1 i t}-a_{m_{3}}[\ldots]\right)}\right)\right]^{y_{1 i t}},}
\end{aligned}
$$

where $w_{m_{k}}, a_{m_{k}}$ and $M_{k}(k=1,2,3)$ are respectively the weights, abscissae and total number of points of the quadrature in each stage, and $a_{m_{k}}[\ldots]=\frac{a_{m_{k}} \sigma_{a_{k}} \sqrt{2}}{\sqrt{\underline{\Lambda_{k k}}}}$. The FIML estimates of the structural parameters of the model where $y_{1 i t}^{*}$ enters the APF are obtained by maximizing $\ln l_{1}$ subject to the constraints defined in equations (3.7a)-(3.7c).

The evaluation of $l_{2}$ is done in a similar fashion and yields a similar expression except that the underlined parameters are replaced by their non-underlined equivalents and that $\gamma_{1} A_{1 i t}$ is replaced by $\gamma_{1} y_{1 i t}$. The FIML estimates of the structural parameters of the model where $y_{1 i t}$ enters the $\mathrm{APF}$ are obtained by maximizing $\ln l_{2}$ without additional constraints.

The performance of the Gauss-Hermite quadrature is worth mentioning. It is known to be inaccurate if the panel size, $T_{i}$, or intraclass correlation, also known as equicorrelation, is large. ${ }^{28}$ For instance, Rabe-Hesketh et al. (2005) show that, in the context of a random-effect probit, the quadrature yields biased estimates when $T_{i}=10$ with an equicorrelation of 0.9 , or for any equicorrelation greater than or equal to 0.45 when $T_{i}=100$ (see also Lee, 2000). However, Raymond (2007, chapter 3) shows that the quadrature works very well in the context of dynamic sample selection models with a panel of small size $\left(T_{i}=4\right)$ and equicorrelation between 0.3 and 0.5 , the latter range being that of the equicorrelation when these models are estimated on the

\footnotetext{
${ }^{28}$ In the context of panel data, the intraclass correlation is a special form of serial correlation. It is defined as $\frac{\sigma_{a_{j}}^{2}}{\sigma_{a_{j}}^{2}+\sigma_{\epsilon_{j}}^{2}}(j=1,2,3)$.
} 
Dutch innovation survey data. Thus, we expect the quadrature to produce accurate estimates. ${ }^{29}$ Evidently, we would need to carry out Monte Carlo analyses that use our nonlinear dynamic simultaneous equations models as a benchmark in order to assess the extent of the accuracy of the quadrature in these models. This is beyond the scope of our analysis and is left for future research.

\section{Appendix B Models with $y_{2 i t}^{*}$ or $y_{2 i t}$ as a predictor of labor productivity}

\section{Model with latent share of innovative sales}

The model with latent share of innovative sales as a predictor of labor productivity consists of equations (2.1)-(2.4) and (2.5a) with $j=2$ in equation (2.5a). These equations constitute the structural form of the model. The reduced-form equations are given by equations (2.1)-(2.4) and

$$
y_{3 i t}=\vartheta_{33} y_{3 i, t-1}+\boldsymbol{\beta}_{3}^{\prime} \mathbf{x}_{3 i t}+\gamma_{2}\left[\vartheta_{22} y_{2 i, t-1}+\vartheta_{23} y_{3 i, t-1}+\boldsymbol{\beta}_{2}^{\prime} \mathbf{x}_{2 i t}\right]+\underbrace{\gamma_{2} \alpha_{2 i}+\alpha_{3 i}}_{\underline{\alpha_{3 i}}}+\underbrace{\gamma_{2} \varepsilon_{2 i t}+\varepsilon_{3 i t}}_{\underline{\epsilon_{3 i t}}},
$$

where $y_{2 i t}^{*}$ has been replaced by its right-hand side expression of equation (2.3). The relations between the underlined components of $\underline{\boldsymbol{\Sigma}_{\varepsilon}}$ and $\underline{\boldsymbol{\Sigma}_{\boldsymbol{a}}}$ and the structural counterparts become

$$
\begin{array}{rlrl}
\underline{\sigma_{\varepsilon_{3}}} & =\gamma_{2}^{2} \sigma_{\varepsilon_{2}}^{2}+\sigma_{\varepsilon_{3}}^{2}+2 \gamma_{2} \rho_{\varepsilon_{2} \varepsilon_{3}} \sigma_{\varepsilon_{2}} \sigma_{\varepsilon_{3}}, & \underline{\sigma_{a_{3}}^{2}} & =\gamma_{2}^{2} \sigma_{a_{2}}^{2}+\sigma_{a_{3}}^{2}+2 \gamma_{2} \rho_{a_{2} a_{3}} \sigma_{a_{2}} \sigma_{a_{3}}, \\
\underline{\rho_{\varepsilon_{1} \varepsilon_{3}}}=\frac{\gamma_{2} \rho_{\varepsilon_{1} \varepsilon_{2}} \sigma_{\varepsilon_{2}}+\rho_{\varepsilon_{1} \varepsilon_{3}} \sigma_{\varepsilon_{3}}}{\left(\gamma_{2}^{2} \sigma_{\varepsilon_{2}}^{2}+\sigma_{\varepsilon_{3}}^{2}+2 \gamma_{2} \rho_{\varepsilon_{2} \varepsilon_{3}} \sigma_{\varepsilon_{2}} \sigma_{\varepsilon_{3}}\right)^{\frac{1}{2}}}, & \underline{\rho_{a_{1} a_{3}}} & =\frac{\gamma_{2} \rho_{a_{1} a_{2}} \sigma_{a_{2}}+\rho_{a_{1} a_{3}} \sigma_{a_{3}}}{\left(\gamma_{2}^{2} \sigma_{a_{2}}^{2}+\sigma_{a_{3}}^{2}+2 \gamma_{2} \rho_{a_{2} a_{3}} \sigma_{a_{2}} \sigma_{a_{3}}\right)^{\frac{1}{2}}}, \\
\underline{\rho_{\varepsilon_{2} \varepsilon_{3}}}=\frac{\gamma_{2} \sigma_{\varepsilon_{2}}+\rho_{\varepsilon_{2} \varepsilon_{3}} \sigma_{\varepsilon_{3}}}{\left(\gamma_{2}^{2} \sigma_{\varepsilon_{2}}^{2}+\sigma_{\varepsilon_{3}}^{2}+2 \gamma_{2} \rho_{\varepsilon_{2} \varepsilon_{3}} \sigma_{\varepsilon_{2}} \sigma_{\varepsilon_{3}}\right)^{\frac{1}{2}}}, & \underline{\rho_{a_{2} a_{3}}} & =\frac{\gamma_{2} \sigma_{a_{2}}+\rho_{a_{2} a_{3}} \sigma_{a_{3}}}{\left(\gamma_{2}^{2} \sigma_{a_{2}}^{2}+\sigma_{a_{3}}^{2}+2 \gamma_{2} \rho_{a_{2} a_{3}} \sigma_{a_{2}} \sigma_{a_{3}}\right)^{\frac{1}{2}}} .
\end{array}
$$

The likelihood function of this model is similar to $l_{1}$ except that $\gamma_{1} A_{1 i t}$ is replaced by $\gamma_{2} A_{2 i t}$ where $A_{2 i t}$ is defined in equation (3.11a). The FIML estimates of the structural parameters are obtained by maximizing the log-likelihood subject to the constraints (B.2a)-(B.2c) in lieu of (3.7a)-(3.7c).

\section{Model with observed share of innovative sales}

The model with observed share of innovative sales as a predictor of labor productivity consists of equations (2.1)-(2.4) and (2.5b) with $j=2$ in equation (2.5b). The likelihood function of this model is similar to $l_{1}$ except that the underlined parameters are replaced by their non-underlined equivalents and that $\gamma_{1} A_{1 i t}$ is replaced by $\gamma_{2} y_{2 i t}$. The FIML estimates of the structural parameters of this model are obtained by maximizing the log-likelihood with no additional constraints.

\footnotetext{
${ }^{29}$ The equicorrelation is about 0.1 when the dynamic sample selection models are estimated on the French innovation survey data. Thus, the poor performance of the Gauss-Hermite quadrature is even less of an issue.
} 


\section{Appendix C Labor productivity elasticity of the share of innovative sales}

Let the productivity equation be written as

$$
\ln \left(y_{3 t}\right)=\gamma_{2} \operatorname{logit}\left(y_{2 t}\right)+\ldots+\varepsilon_{3 t}
$$

where $y_{3 t}$ denotes productivity, $y_{2 t}$ denotes the share of innovative sales and $\operatorname{logit}\left(y_{2 t}\right)=\ln \left(\frac{y_{2 t}}{1-y_{2 t}}\right) \cdot{ }^{30}$ The labor productivity elasticity of the share of innovative sales, denoted by $E l_{y_{3 t}, y_{2 t}}$, is by definition $\partial \ln \left(y_{3 t}\right) / \partial \ln \left(y_{2 t}\right)$ and is derived as

$$
E l_{y_{3 t}, y_{2 t}}=\frac{\partial \ln \left(y_{3 t}\right)}{\partial \operatorname{logit}\left(y_{2 t}\right)} \frac{\partial \operatorname{logit}\left(y_{2 t}\right)}{\partial \ln \left(y_{2 t}\right)}=\gamma_{2} \frac{\partial \operatorname{logit}\left(y_{2 t}\right)}{\partial \ln \left(y_{2 t}\right)}
$$

By making the variable change $v_{2 t}=\ln \left(y_{2 t}\right)$ and writing

$$
\operatorname{logit}\left(y_{2 t}\right)=v_{2 t}-\ln \left[1-e^{v_{2 t}}\right]
$$

we can derive $\partial \operatorname{logit}\left(y_{2 t}\right) / \partial \ln \left(y_{2 t}\right)$ as

$$
\frac{\partial \operatorname{logit}\left(y_{2 t}\right)}{\partial \ln \left(y_{2 t}\right)}=\frac{\partial \operatorname{logit}\left(y_{2 t}\right)}{\partial v_{2 t}}=\frac{1}{1-e^{v_{2 t}}}=\frac{1}{1-y_{2 t}}
$$

The elasticity is then written as

$$
E l_{y_{3 t}, y_{2 t}}=\frac{\gamma_{2}}{1-y_{2 t}}
$$

and is to be evaluated at values of interest (e.g. sample mean) of the share of innovative sales (in level). When the latent share of innovative sales enters the productivity equation, we evaluate this elasticity at predicted values of interest of the latent share of innovative sales.

Since $E l_{y_{3 t}, y_{2 t}}$ is a linear function of $\gamma_{2}$, the standard error of the estimated elasticity is straightforwardly obtained as

$$
\operatorname{S.E.}\left(\widehat{E l}_{y_{3 t}, y_{2 t}}\right)=\frac{S . E \cdot\left(\widehat{\gamma_{2}}\right)}{1-y_{2 t}} \text {. }
$$

\footnotetext{
${ }^{30}$ For simplicity in the notation, we discard the firm subscript $i$, the other regressors and the individual effects.
} 


\section{Appendix D FIML estimates with $y_{1 i t}^{*}$ in the labor produc- tivity equation and distance to frontier regres-}

\section{sors}

Table 10: FIML estimates of the model with latent innovation propensity to explain productivity and with distance to frontier regressors: Unbalanced panel from Dutch and French CIS 2, CIS 3 and CIS $4^{\ddagger}$

\begin{tabular}{|c|c|c|c|c|}
\hline \multirow[t]{3}{*}{ Variable } & Slope & (Std. Err.) & Slope & (Std. Err.) \\
\hline & \multicolumn{2}{|c|}{ France } & \multicolumn{2}{|c|}{ The Netherlands } \\
\hline & \multicolumn{4}{|c|}{ Innovation occurrence $_{t}$} \\
\hline Innovation occurrence $_{t-1}$ & $0.071^{\dagger}$ & $(0.042)$ & 0.025 & $(0.066)$ \\
\hline Innovation occurrence $_{0_{i}}, 3$ waves & 0.068 & $(0.044)$ & $0.282^{* *}$ & $(0.074)$ \\
\hline Innovation occurrence $0_{i}, 2$ waves & $0.137^{* *}$ & $(0.024)$ & $0.275^{* *}$ & $(0.038)$ \\
\hline \multicolumn{5}{|l|}{ Distance to frontier } \\
\hline$\left(\mathrm{D}_{\mathrm{Q}_{2}}\right)_{t-1}$ & 0.019 & $(0.031)$ & 0.018 & $(0.043)$ \\
\hline$\left(\mathrm{D}_{\mathrm{Q}_{3}}\right)_{t-1}$ & 0.015 & $(0.032)$ & 0.025 & $(0.043)$ \\
\hline$\left(\mathrm{D}_{\mathrm{Q}_{4}}\right)_{t-1}$ & 0.035 & $(0.035)$ & 0.050 & $(0.046)$ \\
\hline$(\mathrm{R} \& \mathrm{D} / \text { employee })_{t-1}$, in log & 0.011 & $(0.011)$ & $0.070^{* *}$ & $(0.018)$ \\
\hline$\left(D_{\text {non-continuous }} R \& D\right)_{t-1}$ & $-0.202^{* *}$ & $(0.028)$ & $-0.233^{* *}$ & $(0.037)$ \\
\hline \multicolumn{5}{|l|}{ Size class } \\
\hline $\mathrm{D}_{\#}$ employees $\leq 50$ & $-0.174^{* *}$ & $(0.051)$ & -0.104 & $(0.067)$ \\
\hline $\mathrm{D}_{50}<\#$ employees $\leq 250$ & $-0.131^{* *}$ & $(0.035)$ & -0.014 & $(0.056)$ \\
\hline $\mathrm{D}_{250<\# \text { employees } \leq 500}$ & -0.099 & $(0.076)$ & 0.130 & $(0.111)$ \\
\hline \multirow[t]{2}{*}{ Market share $_{t-1}$, in log } & $0.033^{* *}$ & $(0.011)$ & $0.036^{* *}$ & $(0.012)$ \\
\hline & \multicolumn{4}{|c|}{ Share of innovative sales $t$, in logit } \\
\hline Share of innov. sales $t-1$, in logit & $0.116^{*}$ & $(0.049)$ & 0.046 & $(0.043)$ \\
\hline Share of innov. sales $0_{i}, 3$ waves & 0.057 & $(0.046)$ & $0.130^{* *}$ & $(0.040)$ \\
\hline Share of innov. sales $0_{i}, 2$ waves & $0.185^{* *}$ & $(0.026)$ & $0.171^{* *}$ & $(0.027)$ \\
\hline \multicolumn{5}{|l|}{ Distance to frontier } \\
\hline$\left(\mathrm{D}_{\mathrm{Q}_{2}}\right)_{t-1}$ & $0.305^{*}$ & $(0.132)$ & 0.040 & $(0.146)$ \\
\hline$\left(\mathrm{D}_{\mathrm{Q}_{3}}\right)_{t-1}$ & 0.055 & $(0.136)$ & 0.046 & $(0.147)$ \\
\hline$\left(\mathrm{D}_{\mathrm{Q}_{4}}\right)_{t-1}$ & 0.072 & $(0.147)$ & -0.255 & $(0.159)$ \\
\hline$(\mathrm{R} \& \mathrm{D} / \text { employee })_{t-1}$, in log & 0.069 & $(0.044)$ & $0.123^{* *}$ & $(0.031)$ \\
\hline$\left(\mathrm{D}_{\text {non-continuous }} \mathrm{R} \& \mathrm{D}\right)_{t-1}$ & $-0.319^{* *}$ & $(0.101)$ & $-0.249^{* *}$ & $(0.143)$ \\
\hline \multicolumn{5}{|l|}{ Size class } \\
\hline $\mathrm{D}_{\#}$ employees $\leq 50$ & 0.369 & $(0.238)$ & 0.308 & $(0.230)$ \\
\hline $\mathrm{D}_{50}<\#$ employees $\leq 250$ & 0.144 & $(0.157)$ & 0.104 & $(0.188)$ \\
\hline 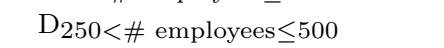 & 0.269 & $(0.127)$ & 0.196 & $(0.233)$ \\
\hline \multirow[t]{2}{*}{ Market share $t-1$, in log } & $0.056^{* *}$ & $(0.002)$ & $0.043^{*}$ & $(0.020)$ \\
\hline & \multicolumn{4}{|c|}{ Labor productivity ${ }_{t}$ sales/employee, in log } \\
\hline$(\text { Sales/employee })_{t-1}$, in log & $0.531^{* *}$ & $(0.056)$ & $0.324^{* *}$ & $(0.066)$ \\
\hline$(\text { Sales/employee })_{0_{i}}, 3$ waves & $0.337^{* *}$ & $(0.056)$ & $0.280^{* *}$ & $(0.066)$ \\
\hline$(\text { Sales/employee })_{0_{i}}, 2$ waves & $0.857^{* *}$ & $(0.012)$ & $0.587^{* *}$ & $(0.024)$ \\
\hline Latent innovation propensity $t$ & $0.080^{* *}$ & $(0.021)$ & $0.124^{* *}$ & $(0.029)$ \\
\hline$(\text { Investment/employee })_{t}$, in log & $0.065^{* *}$ & $(0.006)$ & $0.119^{* *}$ & $(0.012)$ \\
\hline Employment $_{t}$, in log & $-0.029^{* *}$ & $(0.009)$ & $-0.083^{* *}$ & $(0.018)$ \\
\hline \# observations & \multicolumn{2}{|c|}{2505} & \multicolumn{2}{|c|}{1639} \\
\hline Log-likelihood & \multicolumn{2}{|c|}{-5045.059} & \multicolumn{2}{|c|}{-3918.637} \\
\hline
\end{tabular}

The notion of technological frontier is mostly used in the macroeconomic literature on growth 
convergence. Among various testable hypotheses one is that innovation becomes more important as an economy approaches the world technology frontier (see e.g. Acemoglu et al., 2003, 2006). We can identify in each 3-digit industry the enterprise with the largest productivity and then define for each enterprise a technology gap variable as the difference between the largest productivity within each 3-digit industry and the productivity of the enterprise belonging to that industry. Then, looking at the distribution (within each industry) of the technology gap variable, we define three dummy variables $\mathrm{D}_{\mathrm{Q}_{2}}, \mathrm{D}_{\mathrm{Q}_{3}}$ and $\mathrm{D}_{\mathrm{Q}_{4}}$ which take the value one if the technology gap lies respectively between the first $(>)$ and second quartile $(\leq)$, the second $(>)$ and the third quartile $(\leq)$, and above $(>)$ the third quartile. The dummy variable $\mathrm{D}_{\mathrm{Q}_{1}}$, which takes the value one if the technology gap lies below or at the first quartile, is used as the reference. Firms for which $\mathrm{D}_{\mathrm{Q}_{1}}$ is equal to one are the closest to the technological frontier. If the above-mentioned hypothesis is satisfied, we expect the effects of $D_{Q_{2}}, D_{Q_{3}}$ and $D_{Q_{4}}$ to be negative and statistically significant. We consider the lagged values of the dummy variables in the estimation for the same reason as for the market share regressor. Furthermore, these dummy variables capture not only the distance to technological frontier but also a type of (indirect) feedback effect of productivity on innovation. As a result, in order to avoid multicollinearity problems, whenever these dummy variables are included in the estimation, the above-mentioned feedback effect of productivity is ignored, i.e. we assume $\vartheta_{13}=\vartheta_{23}=0$.

Since the results with the distance to frontier regressors are very similar across model specifications, we report them only for the model with the innovation propensity as a predictor of labor productivity (see Table 10). In other words, we still observe a unidirectional causality running from innovation to productivity with the lagged distance to frontier dummies being insignificant. The remaining estimation results can be obtained upon request.

\section{Acknowledgment}

The authors wish to thank an anonymous referee and the participants of the various seminars where this paper has been presented for their comments and suggestions, in particular Stéphane Robin, Ulya Ulku and Adrian Wood.

\section{References}

Abramowitz, M., Stegun, I. A., 1964. Handbook of Mathematical Functions with Formulas, Graphs, and Mathematical Tables. National Bureau of Standards Applied Mathematics, US Government 
Printing Office, Washington, D.C..

Acemoglu, D., Aghion, P., Zilibotti, F., 2003. Vertical integration and distance to frontier. Journal of the European Economic Association 1, 630-638.

Acemoglu, D., Aghion, P., Zilibotti, F., 2006. Distance to frontier, selection, and economic growth. Journal of the European Economic Association 4, 37-74.

Bailey, M. N., Hulten, C., Campbell, D., Bresnahan, T., Caves, R. E., 1992. Productivity dynamics in manufacturing plants. Brookings Papers on Economic Activity. Microeconomics, 187-267.

Bartelsman, E. J., Dhrymes, P. J., 1998. Productivity dynamics: U.S. manufacturing plants, 19721986. Journal of Productivity Analysis 9, 5-34.

Bhattacharya, S., Ritter, J. R., 1983. Innovation and communication: Signalling with partial disclosure. Review of Economic Studies 50, 331-346.

Butler, J. S., Moffitt, R., 1982. A computationally efficient quadrature procedure for the one-factor multinomial probit model. Econometrica 50, 761-764.

Crépon, B., Duguet, E., Mairesse, J., 1998. Research, innovation and productivity: An econometric analysis at the firm level. Economics of Innovation and New Technology 7, 115-158.

Davidson, R., MacKinnon, J. G., 1981. Several tests for model specification in the presence of alternative hypotheses. Econometrica 49, 781-793.

Duguet, E., 2006. Innovation height, spillovers and TFP growth at the firm level: Evidence from French manufacturing. Economics of Innovation and New Technology 15, 415-442.

Fariñas, J. C., Ruano, S., 2005. Firm productivity, heterogeneity, sunk costs and market selection. International Journal of Industrial Organization 23, 505-534.

Flaig, G., Stadler, M., 1994. Success breeds success. The dynamics of the innovation process. Empirical Economics 19, 55-68.

Geroski, P. A., van Reenen, J., Walters, C. F., 1997. How persistently do firms innovate? Research Policy 26, 33-48.

Greene, W. H., 2011. Econometric Analysis, $7^{\text {th }}$ Edition. Prentice Hall, New Jersey.

Griffith, R., Huergo, E., Mairesse, J., Peters, B., 2006. Innovation and productivity across four European countries. Oxford Review of Economic Policy 22, 483-498. 
Griliches, Z., 1979. Issues in assessing the contribution of research and development to productivity growth. Bell Journal of Economics 10, 92-116.

Hall, B. H., Griliches, Z., Hausman, J. A., 1986. Patents and R and D: Is there a lag? International Economic Review 27, 265-283.

Hall, B. H., Lotti, F., Mairesse, J., 2013. Evidence on the impact of R\&D and ict investments on innovation and productivity in Italian firms. Economics of Innovation and New Technology 22, $300-328$.

Hamermesh, D. S., 2007. Viewpoint: Replication in economics. Canadian Journal of Economics 40, 715-733.

Hsiao, C., 2003. Analysis of Panel Data, $2^{\text {nd }}$ Edition. Cambridge University Press.

Huergo, E., Moreno, L., 2011. Does history matter for the relationship between R\&D, innovation and productivity. Industrial and Corporate Change 20, 1335-1368.

Klette, T. J., 1996. R\&D, scope economies and plant performance. RAND Journal of Economics $27,502-522$.

Klette, T. J., Johansen, F., 1998. Accumulation of R\&D capital and dynamic firm performance: A not-so-fixed effect model. Annales d'Economie et de Statistique 49-50, 389-419.

Kotz, S., Balakrishnan, N., Johnson, N. L., 2000. Continuous Multivariate Distributions, $2^{\text {nd }}$ Edition. Vol. 1. John Wiley \& Sons, INC.

Lee, L.-F., 2000. A numerically stable quadrature procedure for the one-factor random-component discrete choice model. Journal of Econometrics 95, 117-129.

Lokshin, B., Belderbos, R., Carree, M., 2008. The productivity effect of internal and external R\&D: Evidence from a dynamic panel data model. Oxford Bulletin of Economics and Statistics $70,399-413$.

Lööf, H., 2005. A comparative perspective on innovation and productivity in manufacturing and services. In: Cantner, U., Dinopoulos, E., Lanzilloti, R. F. (Eds.), Entrepreneurship, the New Economy and Public Policy. Springer-Verlag, pp. 181-202.

Mairesse, J., Mohnen, P., 2010. Using innovation surveys for econometric analysis. In: Hall, B. H., Rosenberg, N. (Eds.), Handbook of the Economics of Innovation. Elsevier, Amsterdam, pp. $1130-1155$. 
Mairesse, J., Mohnen, P., Kremp, E., 2005. The importance of R\&D and innovation for productivity: A reexamination in light of the French innovation survey. Annales d'Économie et de Statistique $79 / 80,487-527$.

Majd, S., Pindyck, R. S., 1987. Time to build, option value, and investment decisions. Journal of Financial Economics 18, 7-27.

OECD, 2007. OECD Science, Technology and Industry Scoreboard 2007: Innovation and Performance in the Global Economy. OECD; 2007 edition, Paris.

Pakes, A., Griliches, Z., 1980. Patents and R\&D at the firm level: A first report. Economics Letters $5,377-381$.

Parisi, M. L., Schiantarelli, F., Sembenelli, A., 2006. Productivity, innovation and R\&D: Micro evidence for Italy. European Economic Review 50, 2037-2061.

Peters, B., 2009. Persistence of innovation: Stylized facts and panel data evidence. Journal of Technology Transfer 34, 226-243.

Rabe-Hesketh, S., Skrondal, A., Pickles, A., 2005. Maximum likelihood estimation of limited and discrete dependent variable models with nested random effects. Journal of Econometrics 128, $301-323$.

Raymond, W., 2007. The dynamics of innovation and firm performance: An econometric panel data analysis. PhD Dissertation, Maastricht University.

Raymond, W., Mohnen, P., Palm, F., Schim van der Loeff, S., 2010. Persistence of innovation in Dutch manufacturing: Is it spurious? Review of Economics and Statistics 92, 495-504.

Vuong, Q. H., 1989. Likelihood ratio tests for model selection and non-nested hypotheses. Econometrica 57, 307-333.

Wooldridge, J. M., 2005. Simple solutions to the initial conditions problem in dynamic nonlinear panel data models with unobserved heterogeneity. Journal of Applied Econometrics 20, 39-54. 